\title{
Uma investigação sobre a aplicação de bônus adicional como política de ação afirmativa na Universidade Federal de Minas Gerais (UFMG)
}

\author{
Juliana Mara Winther* \\ André Braz Golgher*
}

\begin{abstract}
Há algumas décadas tem se destacado a importância dos investimentos em educação para o desenvolvimento individual e regional. Um fator relevante para que haja incremento do capital humano em uma região é a inclusão da maior proporção possível da população local na escola, em todos os níveis de escolaridade. Entre as políticas que promovem essa inserção, destacam-se as ações afirmativas no âmbito da educação. Essas políticas, que incluem o bônus adicional abordado neste artigo, pretendem reduzir as desigualdades dos diferentes grupos sociais, em particular no que se refere ao atendimento escolar, combatendo sistematicamente a discriminação racial. Neste trabalho, discute-se a adoção do bônus adicional no vestibular da UFMG, comparandose, descritivamente no universo da população da $R M B H$, os indivíduos aptos e os não-aptos a ingressarem no ensino superior, bem como confrontando esses primeiros com os que efetivamente estudam nesse nível de ensino. Verificaramse, por meio de simulações com os dados do Enem, os impactos que diferentes políticas de bônus adicional teriam do ponto de vista da inserção dos diferentes grupos de cor e de rendimento familiar. Constatou-se que, em alguns aspectos, essa política não incrementaria o corpo discente da UFMG de indivíduos com menor potencial de aprendizado, embora certas políticas complementares devam ser tomadas com relação a outros fatores.
\end{abstract}

Palavras-chave: Discriminação. Ações afirmativas. Cotas. Bônus adicional.

\section{Introdução}

Há algumas décadas as teorias de desenvolvimento econômico têm destacado a importância dos investimentos em educação para que os países subdesenvolvidos e em vias de desenvolvimento reduzam o gap existente entre eles e os países desenvolvidos. Investir em capital humano, resultando numa mão de obra mais qualificada, é um determinante-chave para o crescimento econômico e a elevação da renda. Além disso, as melhorias no nível de vida de uma população estão estreitamente relacionadas ao aumento da renda via educação (LEE; BARRO, 1997).

O Estado tem papel fundamental nesse quesito, pois determina a estrutura e a qualidade da educação, arquiteta o modelo educacional a ser adotado e tem responsabilidade direta sobre as provisões de educação (BUCHMANN; HANNUM, 2001). Assim, entre os principais objetivos do Estado no âmbito da educação, está a inclusão da maior proporção possível da população

\footnotetext{
* Bacharel em Relações Internacionais pela PUC-MG e em Economia pela Universidade Federal de Minas Gerais - UFMG. Mestranda em Administração Pública pela Fundação João Pinheiro - FJP.

** Doutor em Demografia, professor do Centro de Desenvolvimento e Planejamento Regional - Cedeplar/UFMG.
} 
no sistema educacional em todos os níveis de escolaridade.

A promoção dessa inclusão tende a ser mais difícil em países em desenvolvimento, principalmente naqueles que apresentam um quadro marcante de desigualdade social, como é o caso brasileiro. Esse fato decorre da constatação de que as oportunidades escolares não são iguais para todos os grupos sociais no Brasil, havendo fortes diferenciais nos níveis educacionais nos diversos estratos da sociedade (SILVA; HASENBALG, 2001).

São vários os fatores que determinam o nível de escolarização e a qualidade de ensino absorvida pelos indivíduos, abrangendo características pessoais inatas (tais como cor e gênero), familiares (escolaridade dos pais, renda familiar, número de irmãos), locacionais (localização da escola, zona de residência, proximidade da escola), entre outros.

A família é apontada como um dos aspectos mais decisivos (LEE; BARRO, 1997) e, especificamente para o caso brasileiro, possui influência tão relevante quanto os fatores relacionados à escola na promoção da educação (MENEZES-FILHO, 2007). Assim, o histórico educacional da família, por promover a transmissão intergeneracional de posições sociais, é um dos principais fatores de geração de melhores oportunidades de mobilidade social (SILVA; HASENBALG, 2001).

Nesse processo de diferenciação e estratificação social intergeneracional, existe influência da cor ou raça do indivíduo, não só quanto às condições correntes mais precárias de inserção de pretos e pardos, mas também com relação ao processo de acumulação de desvantagens (BUCHMANN; HANNUM, 2001; HASENBALG; SILVA, 1998).

Partindo dessas constatações, devese reconhecer que, além das diferenças sociais existentes entre os diversos grupos populacionais brasileiros, o "preconceito e a discriminação raciais no Brasil são fenômenos presentes e ativos, comprometendo a equidade de tratamento entre os cidadãos e exacerbando os níveis de desigualdade no país" (JACCOUD; BEGHIN, 2002). Assim, segundo Moehlecke (2002), como essas questões estão relacionadas às oportunidades de acesso ao ensino, inclusive em nível superior, é necessário que o governo proponha políticas voltadas ao ensino público.

Nesta perspectiva, cita-se o Plano de Desenvolvimento da Educação (PDE), conjunto de ações do Ministério da Educação (2009), em que a educação é vista de forma integrada, da creche à pós-graduação. Mais de 40 programas que procuram oferecer uma educação básica universal e de qualidade compõem esse plano, sendo quatro os eixos norteadores: educação básica, educação superior, educação profissional e alfabetização.

Especificamente no contexto da educação superior pública, entre outros, o plano tem os seguintes princípios: expansão de oferta de vagas; garantia de qualidade; e promoção de inclusão social. Entre as políticas propostas para o ensino superior (ES) público, destacam-se o recente aumento das vagas e a melhoria de inserção em universidades públicas via o Plano de Reestruturação e Expansão das Universidades Federais (Reuni) e o Plano Nacional de Assistência Estudantil (PNAES). Com relação ao ensino privado em nível superior, o PDE promove inovações nos mecanismos de financiamento do estudante, com mudanças no Fundo de Financiamento ao Estudante do ES (Fies), e também via Programa Universidade para Todos (Prouni), visando a ampliação do ES e a inclusão de grupos desfavorecidos.

Assim, dadas essas diferentes políticas de expansão do ES, as ações afirmativas voltadas para este nível de ensino público perpassam justamente os três princípios do PDE citados anteriormente, diminuindo a dificuldade de grupos não favorecidos em sua inserção na sociedade. Essas políticas buscam reduzir a discriminação e a desigualdade social em diferentes áreas, inclusive com relação ao acesso ao ES público, objetivando corrigir as desigualdades historicamente impostas a determinados grupos sociais e/ou étnico-raciais (GOMES, 2003). Dada essa perspectiva histórica, as ações afirmativas pretendem combater sistematicamente a discriminação, reduzir 
as desigualdades e buscar a integração dos diferentes grupos sociais existentes (MOEHLECKE, 2002).

Esse autor justifica a adoção de tais políticas no fundamento jurídico e normativo: tratar desiguais como desiguais. Entretanto, segundo o artigo 5o da Constituição Federal: "Todos são iguais perante a lei, sem distinção de qualquer natureza, garantindo-se aos brasileiros e aos estrangeiros residentes no País a inviolabilidade do direito à vida, à liberdade, à igualdade, à segurança e à propriedade". Ainda assim, segundo Moehlecke (2002), as ações afirmativas se justificam, pois tratar desiguais como iguais somente amplia a desigualdade inicial. Ou seja, cabe aqui uma possível contradição entre a busca por eliminar desigualdades historicamente acumuladas e a igualdade legal corrente no país.

Mesmo considerando essa possibilidade de divergências na análise legal, algumas propostas inclusivas têm sido formuladas no Brasil nas últimas décadas. Nos anos 1980, em projeto de lei, estavam incluídos, entre outros, os seguintes itens que procuravam mitigar as diferenças sociais e raciais no país: concessão diferenciada de bolsas de estudo; e incorporação da imagem positiva da família afro-brasileira ao sistema de ensino e à literatura didática e paradidática. $\mathrm{Na}$ década de 1990 , outras práticas e propostas tomaram corpo, que visavam manter uma proporcionalidade étnica/racial na escola pública em todos os níveis, tais como: mudanças no sistema de ingresso nas instituições de ES, pelo sistema de cotas, pela utilização das taxas proporcionais, ou pela implementação de sistemas de testes alternativos ao vestibular. $\mathrm{Na}$ década seguinte, efetiva-se a adoção de cotas e de bônus adicional ao processo seletivo em diferentes universidades no Brasil, que são as ações afirmativas mais discutidas atualmente no país (MOEHLECKE, 2002).

Ou seja, existe um movimento crescente de políticas de ações afirmativas no âmbito do ES público, mas há várias divergências em relação a essas políticas, inclusive as legais descritas anteriormente. Jaccoud e Beghin (2002) apontam quatro argumentos que se contraporiam a essas políticas: ferem o princípio da isonomia (tratar iguais como iguais); desconsideram o mérito; desviam a atenção do real problema da pobreza, concentrando-se na questão racial; e desconsideram a miscigenação como fator que impossibilita definir no Brasil quem é ou não negro. Além disso, há divergências e ambiguidades com relação aos benefícios da implantação das ações afirmativas (FERMAN; ASSUNÇÃO, 2005), e se cabe à universidade corrigir por meio dessas ações as deficiências da educação básica brasileira (FREITAS, 2006).

Quanto a esse último ponto, deve-se ressaltar que ações afirmativas possuem caráter emergencial e transitório, sendo que a continuidade das mesmas está sujeita a análise após avaliação de seus resultados iniciais. A tendência é melhorar e adaptar o sistema para uma efetiva inclusão do grupo socialmente desfavorecido (GOMES, 2003). Entretanto, dado esse caráter emergencial, tais políticas de forma alguma substituem um maior investimento em meIhorias nos ensinos fundamental e médio públicos, ao contrário, promovem uma discussão sobre, justamente, a precariedade da escola básica gratuita brasileira. Porém, uma melhoria do sistema de ensino é uma política com prazo de maturação maior, o que justifica a proposição de políticas públicas alternativas.

Ferman e Assunção (2005) tratam da questão dos benefícios e ambiguidades das políticas de ações afirmativas em um estudo para o caso brasileiro. Os autores afirmam que essas ações podem aumentar os incentivos à parcela da população que seria beneficiada pela política, já que as oportunidades antes não percebidas por ela passam a ser mais tangíveis. Entretanto, os efeitos podem ser ambíguos, uma vez que essa mesma população favorecida pode se acomodar com o benefício. Assim, há várias controvérsias quanto aos efeitos positivos e negativos dessa política, inclusive com relação aos não favorecidos pela política.

Fryer e Loury (2005) contribuíram para a discussão desse tema, destacando alguns mitos com relação a essa ação afirmativa, muitos presentes na discussão acima. Os autores apontam como mitos: 
- ações afirmativas devem envolver objetivos e prazos, mas não devem definir cotas definitivamente;

- políticas que não distinguem os indivíduos por cor oferecem um eficiente substituto para aquelas que se baseiam na cor dos indivíduos;

- ações afirmativas criam oportunidades, mas não produzem incentivos;

- leis de oportunidades igualitárias são suficientes para garantir a equidade racial;

- quanto antes as políticas de ações afirmativas forem implementadas na educação ou no desenvolvimento da carreira, melhor;

- muitos brancos (parcela não favorecida dessas políticas) são diretamente afetados pelas ações afirmativas designadas a aumentar a representação das minorias;

- ações afirmativas sempre beneficiam os favorecidos.

Os autores se posicionam de modo favorável à adoção de cotas como ação afirmativa para os grupos de cor desfavorecidos, uma vez que os benefícios para esses seriam substanciais. Já em relação ao grupo de não-beneficiados pelas políticas, os autores afirmam que, mesmo que uma parcela considerável da população tenha sido nãoselecionada por causa dessa política, o que de forma geral não é o que acontece, isso provavelmente não teria grande impacto no longo prazo para esses indivíduos.

Mesmo com controvérsias, divergências e ambiguidades, algumas medidas favoráveis às cotas ou ao bônus adicional já são adotadas no Brasil (MOEHLECKE, 2002). No caso particular da Universidade Federal de Minas Gerais (UFMG), foi criado em 2003 o Programa de Ações Afirmativas. A proposta privilegiou ações de estímulo à permanência dos negros nos cursos de graduação, a partir do fortalecimento do percurso acadêmico desses estudantes, que são em grande parte oriundos de famílias de baixa renda (GOMES; MARTINS, 2004). Esse programa, que está sendo ampliado e implementado na UFMG, é pautado na ideia de que a universidade pública tem o dever e o compromisso social de reduzir os efeitos antidemocráticos dos processos de seleção e de exclusão impostos aos negros brasileiros.

Essas medidas estão inseridas na discussão recente sobre "que universidade queremos" (ADRIOLA et al., 2009; ALMEIDA, 2009; DOMINGUES, 2008). Segundo Adriola et al. (2009), citando Belloni (1992), a principal função da universidade é gerar saber. Entretanto, segundo os mesmos autores, a universidade é uma instituição social e, assim, deve, além de gerar conhecimentos, formar profissionais de qualidade e disponibilizar conhecimentos e profissionais para a sociedade. Ou seja, a universidade está necessariamente arvorada sobre o tripé "pesquisa, ensino e extensão" e, portanto, tem diferentes funções, entre as quais podem ser citadas a mobilidade social para os filhos e filhas das famílias operárias; e servir de paradigma de aplicação de políticas nacionais, como igualdade de oportunidades para mulheres e minorias raciais (ADRIOLA et al., 2009).

Dessa forma, não cabe apresentar a universidade, por exemplo, como voltada para a pesquisa de ponta ou para outro fator específico, mas sim abarcando uma visão plural com múltiplos objetivos e aptidões.

Tendo em vista essas várias funções e as divergências de opinião quanto à inclusão de grupos desfavorecidos na universidade, vê-se a importância de ampliar a discussão sobre propostas concretas de democratização da universidade pública brasileira via a adoção de ações afirmativas. Dessa maneira, o objetivo desse trabalho é fornecer dados e análises para discussão sobre a adoção de bônus adicionais raciais e/ou econômicos na UFMG, a qual atende, principalmente, a estudantes da Região Metropolitana de Belo Horizonte (RMBH).

Assim, uma análise como a realizada no presente estudo para essa região possibilita observar os resultados prováveis da introdução de políticas de bônus adicional nas universidades públicas brasileiras, tendo como base diferenças de raça/etnia, bem como a origem do estudante, se oriundo da escola pública ou da privada. 
Para tanto, esse texto foi dividido em quatro seções. A primeira é essa introdução, que trata principalmente da conceituação teórica sobre as ações afirmativas voltadas para a educação superior. A seção seguinte dedica-se à análise descritiva dos dados, incluindo resultados sobre os indivíduos não-aptos e aptos a ingressarem no ES, além dos estudantes de ES na RMBH, em particular os da UFMG. Foram utilizados dados da Pesquisa Nacional por Amostra de Domicílio (PNAD), de diferentes anos, e da Comissão Permanente do Vestibular da UFMG (Copeve). Em seguida, na terceira seção, inicialmente discutem-se os fatores que impactam no desempenho escolar no ensino médio na RMBH. Para tanto, foram utilizados modelos Mínimos Quadrados Ordinários (MQO) aplicados aos dados do Enem. Posteriormente, se descrevem diferentes simulações realizadas a partir dessa mesma base de dados, com possíveis políticas de bônus adicional no vestibular da UFMG, quanto à composição do corpo discente nessa instituição com relação à cor e ao estrato socioeconômico. Em seguida, foram analisadas possíveis consequências dessas políticas no que se refere ao potencial de aprendizado do aluno que teria sua entrada facilitada na UFMG. Por fim, a última seção conclui o trabalho.

\section{Análise descritiva da escolaridade: RMBH e UFMG}

Conforme ressaltado, dadas as condições de desigualdade no acesso ao ES, políticas como as de ações afirmativas e de cotas buscam diminuir as barreiras de inserção de grupos desfavorecidos. Deve-se ressaltar que a formulação de tais políticas exige sólido conhecimento da população sobre a qual se deseja atuar. Assim, nessa seção, procura-se fazer uma análise descritiva da escolaridade por cor e renda, para diferentes grupos populacionais da $\mathrm{RMBH}$ e os estudantes aprovados no vestibular da UFMG. Além disso, incluem-se dados sobre estudantes universitários em escolas públicas e privadas na $\mathrm{RMBH}$, também como base de comparação.
A análise para a $\mathrm{RMBH}$ foi feita a partir dos microdados das PNADs de 1997, 2002 e 2007. Foram escolhidos dados a partir da década de 1990, por se tratar do período em que as políticas de ação afirmativa, em especial a adoção de cotas ou de bônus adicional, tiveram maior destaque no contexto brasileiro. No entanto, essas políticas destinadas a negros e estudantes originados de escola pública nas universidades públicas somente foram efetivadas depois de 2000. Pretendeu-se, ainda, dar uma periodicidade de cinco anos para os dados da PNAD, sendo que a base de dados mais recente disponível na época da pesquisa era a de 2007.

Já a análise descritiva dos estudantes aprovados no vestibular da UFMG foi realizada por meio de dados fornecidos pela Copeve - Comissão Permanente do Vestibular. Para a inscrição no vestibular, todos os candidatos devem preencher um questionário socioeconômico que abrange, entre outras, informações sobre o indivíduo, seu histórico escolar, sua condição financeira e sua família. Foram utilizados os dados dos questionários dos vestibulares de 2004, 2006 e 2008, pois somente a partir de 2003 foi incorporada uma pergunta referente à cor/raça do indivíduo no questionário. O objetivo foi estudar o atual perfil socioeconômico dos alunos aprovados na UFMG nos respectivos anos, já que a discussão sobre cotas e outros meios de ação afirmativa é recente e pretende atuar exatamente nos ingressantes na universidade. $\mathrm{O}$ acesso aos dados foi feito através de tabelas preparadas pela Copeve sob requisição prévia.

Tendo em vista os objetivos da seção, esta foi dividida em três subseções: a primeira descreve a população apta a ingressar no ES que reside na RMBH; a segunda apresenta o perfil dos estudantes aprovados no vestibular da UFMG; e a última traz a análise comparativa dos grupos, com o intuito de verificar se há viés de seleção na UFMG, incluindo dados sobre os estudantes das universidades públicas e privadas da $\mathrm{RMBH}$.

Perfil dos indivíduos aptos a ingressarem no ensino superior na $R M B H$

A Tabela 1 apresenta dados, para 1997, 2002 e 2005, sobre cor ou raça, tipo de escola 
frequentada no ensino médio e renda domiciliar, segundo diferentes grupos populacionais da RMBH. Quanto à cor ou raça, para facilitar as análises, chamou-se de "brancos" os indivíduos autodeclarados brancos e amarelos, e de "não-brancos" aqueles autodeclarados pretos, pardos e indígenas. Esse agrupamento foi realizado devido às semelhanças socioeconômicas entre os grupos de cor ou raça que são classificados sob a mesma categoria na RMBH (PAIVA; GOLGHER, 2007). Discutem-se, inicialmente, os resultados para toda a população dessa região e, em seguida, para grupos mais específicos. A renda mensal domiciliar é expressa em faixas de salários mínimos (SM), tendo março de 2009 como referência.

A RMBH apresentou aumento populacional entre 1997 e 2007, passando de 3.907 .126 para 5.076.485 habitantes. Houve expansão territorial na RMBH durante o período, mas os municípios acrescidos representam menos de $8 \%$ da população total (MINISTÉRIO DAS CIDADES, 2008), sendo que essa incorporação não altera a tendência geral.
Quanto à cor, a população da RMBH se dividia em proporções semelhantes entre brancos e não-brancos em 1997 e 2002. Entretanto, entre esse último ano e 2007, houve um aumento marcante do percentual de não-brancos (de 49,7\% para 59\%). Essa mesma tendência foi verificada nos dados de Minas Gerais e do Brasil, indicando que existem limitações e particularidade inerentes à autodeclaração de cor.

Os recentes movimentos de orgulho negro e também as políticas pró-grupos desfavorecidos, incluindo toda a discussão de cotas e ações afirmativas, parecem ter influenciado a forma subjetiva de percepção da própria cor por parte do indivíduo. Como consequência, muitos que se classificavam como pardos passaram a se autodeclarar negros e, principalmente, muitos que antes eram brancos passaram a ser negros.

Quanto à renda domiciliar, vê-se que a maioria da população da RMBH encontravase na faixa de até 5 SM nos três anos analisados. Não se percebe tendência marcante ao longo dos anos e, no entanto, qualquer

TABELA 1

Distribuição dos indivíduos, por grupos polulacionais, segundo características socioeconômicas Região Metropoliana de Belo Horizonte - 1997-2007

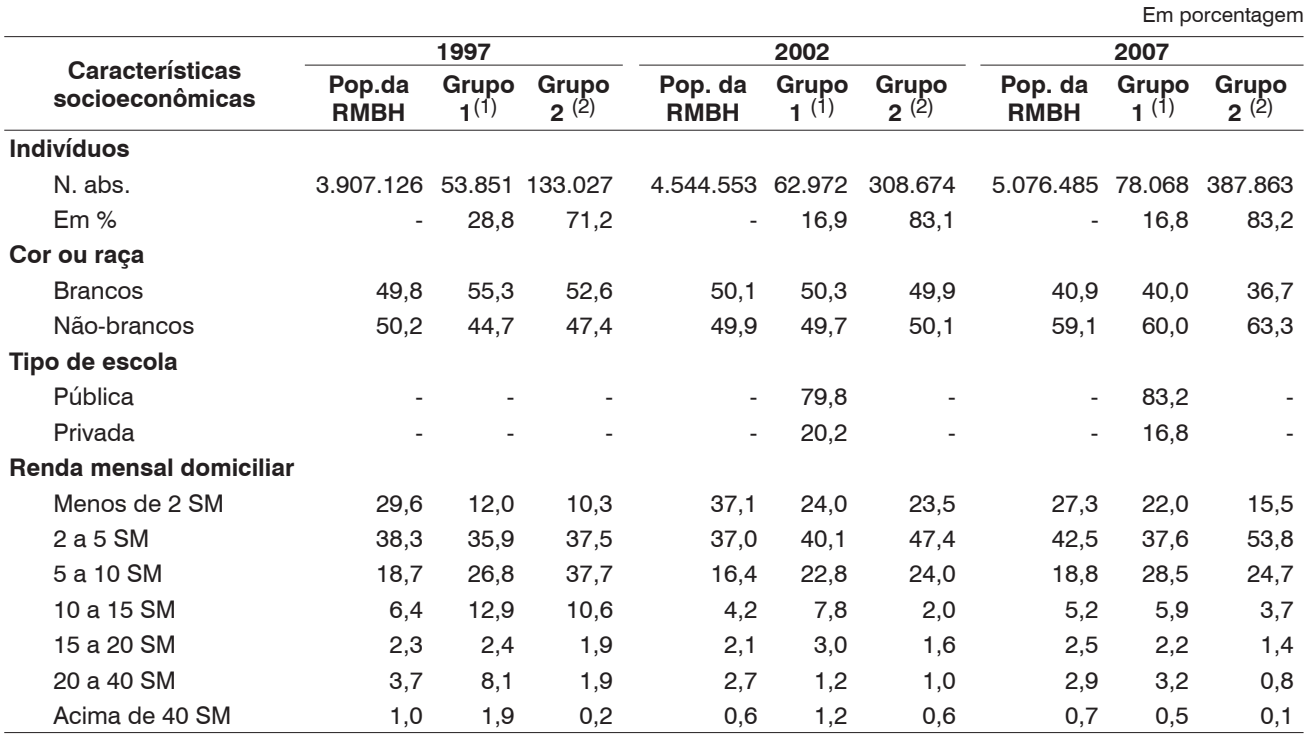

Fonte: IBGE. Pesquisa Nacional por Amostra de Domicílios - PNAD 1997, 2002 e 2007. Elaboração dos autores.

(1) Compreende os estudantes que estavam cursando o último ano do ensino médio.

(2) Compreende os indíviduos que já concluíram o ensino médio, mas ainda não cursavam ensino superior. 
mudança ocorrida seria muito pequena diante da grande desigualdade de renda presente na região.

Além dos dados para a população da $\mathrm{RMBH}$, a Tabela 1 apresenta informações para dois grupos populacionais específicos. Assim, buscou-se selecionar a maioria dos indivíduos da RMBH que teriam escolaridade suficiente e que poderiam pleitear uma vaga na UFMG. Primeiro, foram identificados os estudantes que estavam cursando o último ano do ensino médio (grupo 1) e, depois, os indivíduos que já tinham concluído o ensino médio, mas não estavam cursando qualquer ano do ES (grupo 2). Neste último grupo, a idade de 30 anos foi estabelecida como limite, tendo como base os dados da Copeve da UFMG, que identificou que os indivíduos nesta faixa etária constituem a quase totalidade daqueles que ingressam na UFMG.

A partir dessa seleção, verificou-se que as pessoas consideradas aptas a ingressarem no ES na RMBH correspondiam a cerca de 190 mil em 1997, 377 mil em 2002 e quase 480 mil indivíduos em 2007. Esse incremento no número de indivíduos aptos ao longo dos anos deveu-se, principalmente, ao aumento da escolaridade média na $\mathrm{RMBH}$, uma vez que tal crescimento foi muito superior ao observado pela população em geral. A Tabela 1 detalha os resultados para os dois grupos estudados, sendo que o segundo era muito mais numeroso do que o primeiro nos três anos analisados, em números relativos crescentes, indicando haver na região uma elevada demanda reprimida por ES.

Em 1997, pouco mais de $50 \%$ dos grupos 1 e 2 eram formados por brancos, sendo que a parcela de não-brancos era ligeiramente inferior. Em 2002, as cifras correspondiam a aproximadamente $50 \%$ para cada um dos grupos de cor. Entretanto, entre 2002 e 2007, houve uma variação marcante nesses percentuais, também observada para a população total: os brancos passaram de aproximadamente $50 \%$ para $40 \%$ e comportamento inverso ocorreu com os não-brancos. Isso demonstra que, entre outros aspectos, com a maior tendência de se autodeclarar preto ou pardo no fim do período, há maior proporção de negros concluindo o ensino médio e se tornando aptos a entrarem na universidade.

Portanto, tendo em vista que um percentual mais elevado de não-brancos tem chegado à conclusão do ensino médio na $\mathrm{RMBH}$ a democratização do acesso ao ES para os diferentes grupos de cor pode acontecer, em parte, devido ao aumento dessa população apta a ingressar na universidade. Assim, para a continuidade da inserção dos não-brancos no ES, são fundamentais a universalização do ensino fundamental, a ampliação do ensino médio e a melhoria na qualidade de ambos, como forma de capacitar os jovens a pleitearem uma vaga na universidade.

A Tabela 1 mostra ainda que aproximadamente $80 \%$ dos estudantes no último ano do ensino médio estavam na rede pública. Quando se comparam as distribuições de renda da população da RMBH e dos grupos 1 e 2, nota-se uma dupla seletividade com relação a duas transições na região. Primeiramente, os indivíduos com renda acima de um patamar relativamente baixo (superior a 2 SM em 2007), tornavam-se com maior probabilidade aptos a ingressarem na universidade, uma vez que os grupos com menor renda são relativamente mais numerosos na RMBH. Entre os aptos ocorria um segundo processo seletivo em um patamar mais elevado de renda (aproximadamente $10 \mathrm{SM}$ ), em que aqueles com maior renda passavam a fazer parte do grupo dos universitários com maior probabilidade, enquanto o restante continuava preferencialmente entre os aptos a ingressarem no ES, mas evadiam do sistema de ensino nessa transição entre o ensino médio e o superior.

\section{Perfil dos estudantes aprovados no vestibular da UFMG}

A Tabela 2 apresenta dados para os estudantes aprovados em três dos últimos seis vestibulares da UFMG. Nota-se que, de 2004 a 2008, a universidade aumentou em 120 o número de vagas.

Em relação ao local de residência no momento da inscrição ao vestibular, os alunos aprovados residiam, em sua maioria, na $\mathrm{RMBH}$. No que tange a distinção por cor ou raça, os dados da tabela mostram 
que os brancos predominavam entre os ingressantes na UFMG. Cabe mencionar o aumento expressivo dos estudantes que não desejaram declarar cor ou raça, passando de $5,9 \%$, em 2004, ano em que essa opção de resposta à pergunta proposta foi incorporada ao questionário socioeconômico, para 10,9\%, em 2008. No entanto, para que houvesse uma melhor comparabilidade dos dados, os percentuais para os grupos de cor ou raça foram calculados em $100 \%$, desconsideran- do os que não desejaram declarar. Em sua maioria, os alunos aprovados no vestibular cursaram o ensino médio, inteiramente ou em sua maior parte, em escola privada.

Quanto à distribuição por renda, nota-se certa estabilidade temporal. Aproximadamente $5 \%$ dos estudantes aprovados no vestibular da UFMG se enquadravam na faixa de renda mensal familiar inferior a dois salários mínimos. A maioria dos estudantes aprovados (cerca de $70 \%$ ) se encontrava

TABELA 2

Distribuição dos estudantes aprovados nos vestibulares da Universidade Federal de Minas Gerais, segundo características sociodemográficas 2004-2008

\begin{tabular}{|c|c|c|c|}
\hline \multirow{2}{*}{ Característcas sociodemográficas } & & & n porce \\
\hline & 2004 & 2006 & 2008 \\
\hline Número de vagas oferecidas & 4.594 & 4.674 & 4.714 \\
\hline \multicolumn{4}{|l|}{ Local de residência } \\
\hline Belo Horizonte & 73,2 & 73,7 & 74,4 \\
\hline Periferia da RMBH & 12,0 & 12,4 & 11,1 \\
\hline Interior de MG & 12,4 & 11,4 & 12,1 \\
\hline Outro Estado & 2,1 & 2,3 & 2,3 \\
\hline \multicolumn{4}{|l|}{ Cor ou raça } \\
\hline Brancos & 72,5 & 68,8 & 70,1 \\
\hline Não-brancos & 27,5 & 31,2 & 29,9 \\
\hline Não desejou declarar & 5,9 & 9,8 & 10,9 \\
\hline \multicolumn{4}{|l|}{ Escola que cursou o ensino médio } \\
\hline Pública & 37,7 & 35,3 & 33,0 \\
\hline Privada & 62,3 & 64,7 & 67,0 \\
\hline \multicolumn{4}{|l|}{ Renda mensal familiar } \\
\hline Menos de 2 SM & 5,5 & 5,1 & 5,6 \\
\hline 2 a 5 SM & 23,1 & 23,3 & 23,1 \\
\hline 5 a $10 \mathrm{SM}$ & 25,1 & 27,2 & 26,4 \\
\hline 10 a $15 \mathrm{SM}$ & 15,9 & 17,9 & 20,0 \\
\hline 15 a $20 \mathrm{SM}$ & 11,8 & 11,0 & 10,5 \\
\hline 20 a $40 \mathrm{SM}$ & 13,4 & 10,4 & 10,4 \\
\hline Acima de $40 \mathrm{SM}$ & 4,8 & 4,2 & 3,9 \\
\hline \multicolumn{4}{|l|}{ Escolaridade do pai } \\
\hline Ensino fundamental incompleto & 19,3 & 15,9 & 11,6 \\
\hline Ensino fundamental completo ou ensino médio incompleto & 10,8 & 10,0 & 9,4 \\
\hline Ensino médio completo & 26,2 & 29,3 & 28,7 \\
\hline Ensino superior incompleto ou completo & 42,2 & 43,2 & 47,8 \\
\hline \multicolumn{4}{|l|}{ Escolaridade da mãe } \\
\hline Ensino fundamental incompleto & 17,5 & 12,6 & 9,9 \\
\hline Ensino fundamental completo ou ensino médio incompleto & 9,3 & 9,0 & 8,5 \\
\hline Ensino médio completo & 31,6 & 33,8 & 32,1 \\
\hline Ensino superior incompleto ou completo & 41,1 & 44,1 & 48,8 \\
\hline
\end{tabular}

Fonte: Copeve 2004, 2006 e 2008. Elaboração dos autores. 
nas faixas de renda de 2 a 15 SM e aproximadamente um quarto tinha uma renda acima dessa faixa.

Em relação à escolaridade dos pais, percebe-se que houve aumento no nível de instrução, entre 2004 e 2008. Nesse período, ocorreu redução de aproximadamente $8 \%$ nas parcelas de pais e mães com ensino fundamental incompleto. Por outro lado, observa-se aumento nas proporções com ensino superior incompleto e completo: pais com esse nível de escolaridade representavam, em 2008, mais de $47 \%$ do total, indicando que os ingressantes na UFMG são oriundos de famílias com alto nível de educação formal.

Para compreender melhor a composição dos estudantes aprovados no vestibular da UFMG com relação à cor ou raça por faixa de renda mensal familiar, foi realizada uma análise mais detalhada, em que os estudantes que não desejaram declarar a própria cor ou raça não foram incluídos.

A Tabela 3 mostra a distribuição dos estudantes não-brancos e a razão entre as proporções de não-brancos e brancos, segundo faixas de renda domiciliar. Observa-se que os não-brancos são sobrerrepresentados nas faixas de renda mais baixas, enquanto os brancos são mais representativos nas faixas mais elevadas. A proporção de não-brancos na faixa de menos de 2 SM era mais de duas vezes superior àquela de brancos em todos os anos analisados. Essa razão diminuía com o aumento da renda e, a partir de 10 SM, as proporções de brancos superam as de não-brancos nos três anos.

Há também uma marcante diferenciação do tipo de escola que o estudante havia cursado o ensino médio, de acordo com sua cor ou raça. O Gráfico 1 apresenta a proporção de brancos e não-brancos que estudaram em escola pública durante o EM, entre os aprovados na UFMG no período de 2003-2008. Verifica-se que houve uma leve tendência de queda na participação dos estudantes de escola pública tanto para brancos quanto para não-brancos. O gráfico também evidencia que somente cerca de $30 \%$ dos estudantes brancos e aproximadamente $50 \%$ dos não-brancos vieram de escola pública.

O tipo de escola cursada pelo estudante no ensino médio está diretamente relacionado à sua renda mensal familiar: quanto maior a renda, maior a probabilidade de o indivíduo estudar em escola privada. O Gráfico 2 mostra essa relação de forma bastante clara. Nota-se que até uma renda de cinco salários mínimos, os oriundos de escolas públicas eram maioria, sendo que, a partir dessa faixa, ocorre o contrário. Entretanto, observa-se que, mesmo para rendas relativamente elevadas, acima de $10 \mathrm{SM}$, a proporção de estudantes originados da escola pública girava em torno de $10 \%$. Isso, porém, não indica que eles, em sua maioria, estavam em escolas estaduais e municipais,

TABELA 3

Distribuição dos estudantes não-brancos aprovados no vestibular da Universidade Federal de Minas Gerais e razão entre não-brancos e brancos, segundo faixas de renda familiar 2004-2008

\begin{tabular}{|c|c|c|c|c|c|c|}
\hline \multirow[b]{2}{*}{ Renda familiar } & \multicolumn{2}{|c|}{2004} & \multicolumn{2}{|c|}{2006} & \multicolumn{2}{|c|}{2008} \\
\hline & $\begin{array}{c}\text { Não-brancos } \\
(\%)\end{array}$ & $\begin{array}{c}\text { Razão } \\
\text { não-brancos/ } \\
\text { brancos }\end{array}$ & $\begin{array}{c}\text { Não-brancos } \\
\text { (\%) }\end{array}$ & $\begin{array}{c}\text { Razão } \\
\text { não-brancos/ } \\
\text { brancos }\end{array}$ & $\begin{array}{c}\text { Não-brancos } \\
(\%)\end{array}$ & $\begin{array}{c}\text { Razão } \\
\text { não-brancos/ } \\
\text { brancos }\end{array}$ \\
\hline Menos de 2 SM & 8,89 & 2,16 & 8,79 & 2,66 & 9,29 & 2,30 \\
\hline 2 a 5 SM & 32,99 & 1,69 & 31,40 & 1,55 & 31,33 & 1,60 \\
\hline 5 a 10 SM & 24,44 & 0,98 & 30,14 & 1,14 & 28,85 & 1,15 \\
\hline 10 a $15 \mathrm{SM}$ & 13,25 & 0,77 & 14,60 & 0,75 & 14,98 & 0,67 \\
\hline 15 a $20 \mathrm{SM}$ & 8,97 & 0,70 & 6,83 & 0,52 & 7,21 & 0,60 \\
\hline 20 a 40 SM & 9,57 & 0,63 & 6,04 & 0,48 & 6,25 & 0,52 \\
\hline Acima de $40 \mathrm{SM}$ & 1,88 & 0,31 & 2,20 & 0,44 & 2,08 & 0,42 \\
\hline
\end{tabular}

Fonte: Copeve 2004, 2006 e 2008. Elaboração dos autores. 
GRÁFICO 1

Proporção dos estudantes aprovados nos vestibulares da Universidade Federal de Minas Gerais que vieram da escola pública, segundo cor/raça 2003-2008

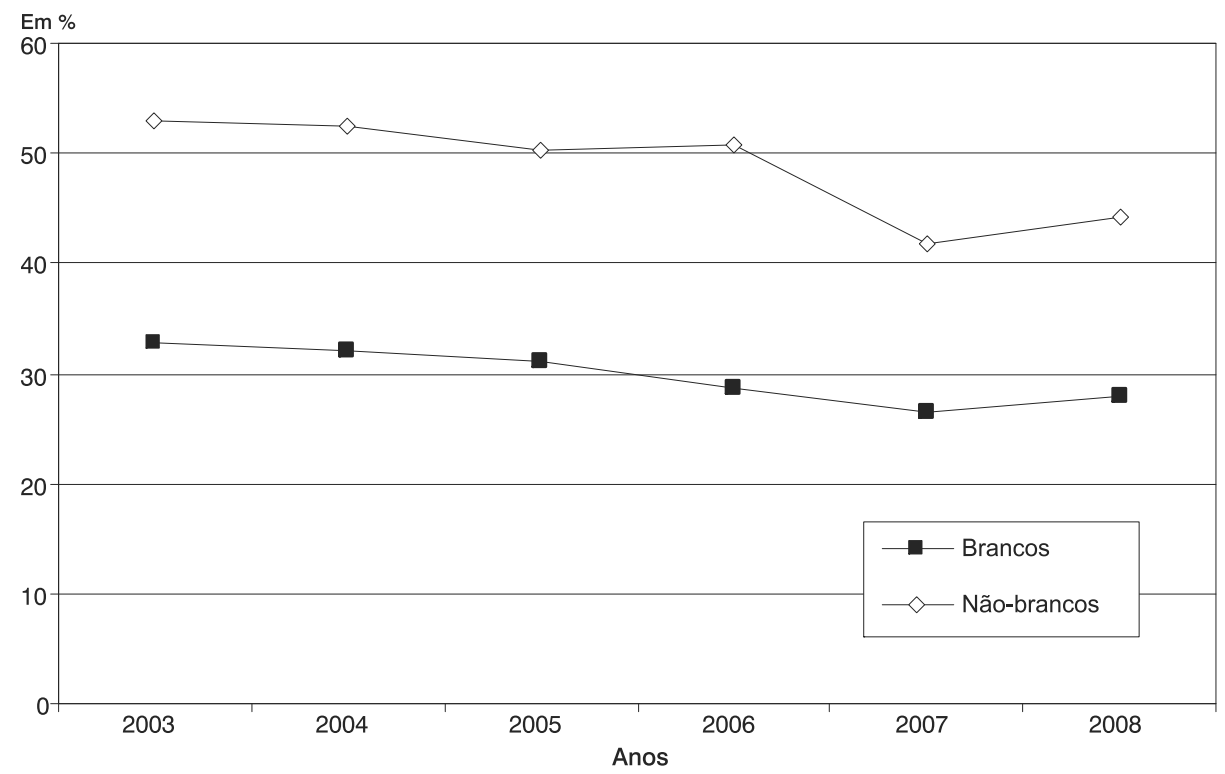

Fonte: Copeve 2003-2008. Elaboração dos autores.

GRÁFICO 2

Distribuição dos estudantes aprovados nos vestibulares da Universidade Federal de Minas Gerais, por escola frequentada no ensino médio, segundo faixas de renda familiar 2008

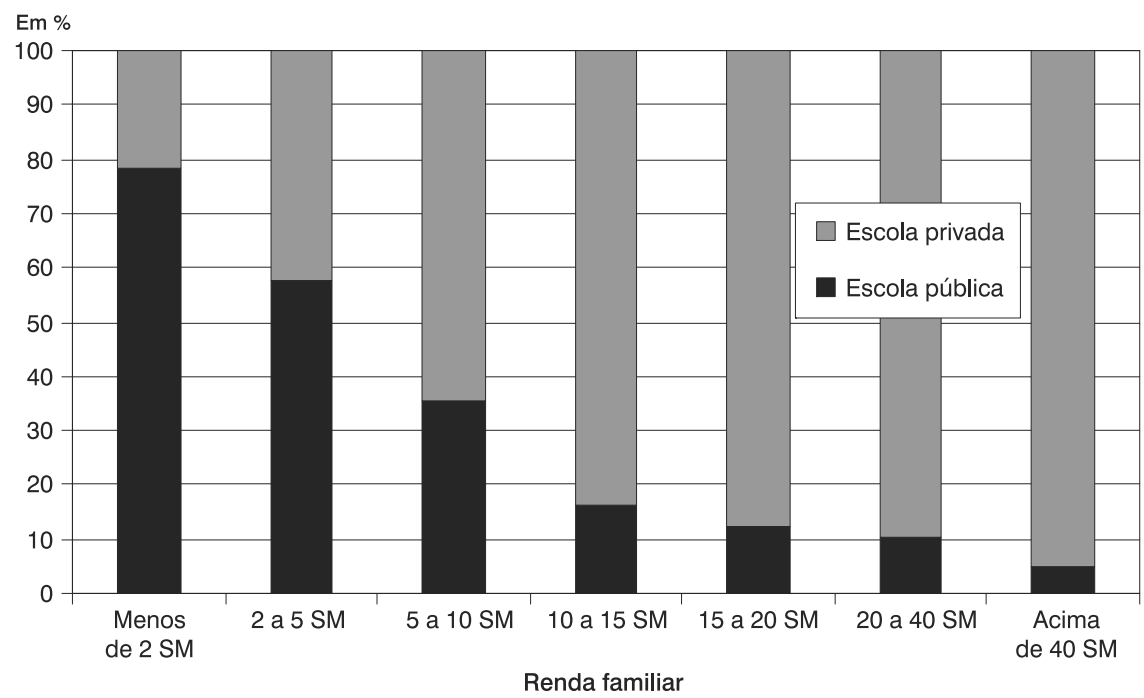

Fonte: Copeve 2008. Elaboração dos autores. 
uma vez que muitos deviam ser estudantes de escolas federais, que, como será visto adiante, apresentam desempenho escolar muito superior às demais públicas.

Um fator importante que influencia fortemente na probabilidade de o indivíduo estudar ou não em diferentes níveis é a educação da mãe, do pai ou da pessoa de referência no domicílio (BARROS et al., 2001). Quanto maior é o nível de instrução dos pais, maior tende a ser a importância dada à educação dos filhos, como discutido na seção anterior (LEE; BARRO, 1997). Como as escolas privadas são, em média, melhores em termos qualitativos do que as públicas, é possível inferir que pais com maior nível de estudo apresentam maior tendência de matricular seus filhos em escolas privadas, mesmo controlando pela renda. Esse fato foi observado para os dados da UFMG.

As descrições apresentadas nessa subseção dão o panorama geral do perfil dos estudantes aprovados nos vestibulares da UFMG de 2004 a 2008, que serão comparados com diferentes grupos de indivíduos da RMBH no próximo item.

\section{Aprovados na UFMG em contraposição a diferentes grupos de indivíduos da $\mathrm{RMBH}$}

Pretende-se, aqui, analisar a abrangência que a UFMG tem com relação à população apta a ingressar no $E S$ da $\mathrm{RMBH}$ e contrastar os diferentes universos populacionais. Para tanto, foi feito um paralelo entre as pessoas dos grupos 1 e 2 descritos anteriormente, aquelas da RMBH que efetivamente estudavam no ES, tanto na rede privada como na pública, e os estudantes aprovados no vestibular da UFMG. Escolheu-se como base comparativa o ano de 2007, ao qual correspondiam os dados mais recentes em todas as bases utilizadas.

A Tabela 4 permite perceber as diferenças entre esses grupos de pessoas da RMBH. Entre os 204.614 estudantes do ES na RMBH, mais de $85 \%$ (175.851) frequentavam instituições privadas, sendo que aqueles que cursavam universidades públicas eram minoria (28.763). ${ }^{1}$ Note-se, ainda, que a UFMG oferecia menos que 5 mil vagas anuais. Dessa forma, pensar a questão da democratização de acesso à educação superior no Brasil abrange não somente o ensino público, mas também outras maneiras de inserção dos estudantes via ensino privado, como proposto pelo PDE.

Assim, qualquer ação afirmativa no ES público somente na UFMG terá pequeno impacto no estoque de indivíduos aptos a ingressarem no ES no curto prazo. Entretanto, do ponto de vista individual, tais políticas tendem a apresentar impacto decisivo nas possibilidades de inserção de grupos menos favorecidos. Além disso, dadas as externalidades positivas do incremento de capital humano, essa melhoria na forma de inserção tem retornos sociais muito superiores aos individuais (MORETTI, 2004), justificando a implementação das políticas de inserção.

Com relação à cor ou raça, a proporção de brancos era muito similar para os que ingressaram na UFMG e para aqueles que estudavam nas universidades públicas na $\mathrm{RMBH}$ (aproximadamente $70 \%$ ), lembrandose que a UFMG é a maior escola pública de ES da região. Já nas instituições privadas e entre aqueles aptos a estudarem no ES, tal percentual correspondia a cerca de $57 \%$ e $40 \%$, respectivamente.

Diferenças marcantes também são observadas com relação ao ensino médio: mais de $80 \%$ dos estudantes do último ano desse nível de ensino da RMBH frequentavam escola pública e somente pouco mais de $30 \%$ do total dos aprovados na UFMG eram originados da rede pública de ensino. Fica claro que os alunos de escola privada têm maior probabilidade de entrar na UFMG do que os de escola pública.

Os dados sobre a renda mensal familiar demonstram que os alunos da UFMG se concentram em faixas de renda mais favorecidas quando comparados com os indivíduos da $\mathrm{RMBH}$ aptos a estudarem. A

\footnotetext{
${ }^{1}$ Deve-se enfatizar que na RMBH há três universidades públicas: UFMG e Cefet-MG, que são federais, e a UEMG, que é estadual.
} 
maior diferença é verificada para renda mensal familiar inferior a $2 \mathrm{SM}$, mostrando que são poucos os indivíduos mais carentes que ingressam na UFMG. Observa-se também certa similaridade entre as universidades públicas e privadas em relação à renda.

Verifica-se, ainda, que a escolaridade da pessoa de referência no domicílio era muito superior para os estudantes aprovados na UFMG do que para os indivíduos aptos. Há, ainda, uma diferença marcante entre a rede pública e a privada de ES, em favor da primeira, significando que os estudantes da rede pública de ES têm familiares com maior nível de escolaridade do que os da privada, mesmo que a distribuição de renda seja similar.

As análises realizadas nessa seção fornecem dados para se conhecer o perfil dos indivíduos nos três universos sobre os quais se está pesquisando: os residentes na RMBH aptos a estudarem no ES; os estudantes nesse nível de ensino na região; e os aprovados no vestibular da UFMG. Os dados descritivos apresentados aqui permitem analisar diversos fatores que confrontam os aprovados na UFMG com outros grupos populacionais na RMBH. Observou-se que existem diferenças marcantes entre esses grupos com relação à distribuição por cor/ raça, renda domiciliar e escolaridade dos pais, fatores que afetam a inclusão no ES.

Outro ponto a ser destacado refere-se aos diferenciais nestes mesmos grupos populacionais quanto à rede de ensino frequentada. Ou seja, são múltiplos os fatores, vários com forte correlação entre si, que definem como se dará a passagem do EM

TABELA 4

Distribuição dos indivíduos aptos a ingressarem no ensino superior e dos estudantes de ensino superior, segundo características socioeconômicas

Região Metropolitana de Belo Horizonte - 2008

Em porcentagem

\begin{tabular}{|c|c|c|c|c|c|c|}
\hline \multirow{2}{*}{ Características socioeconômicas } & \multicolumn{2}{|c|}{$\begin{array}{c}\text { Aptos a } \\
\text { ingressarem no ES }\end{array}$} & \multicolumn{4}{|c|}{ Estudantes de ES } \\
\hline & $\underset{(1)}{\operatorname{Grupo} 1}$ & $\underset{(2)}{\operatorname{Grupo} 2}$ & $\begin{array}{l}\text { Rede } \\
\text { privada }\end{array}$ & $\begin{array}{l}\text { Rede } \\
\text { pública }\end{array}$ & Total & $\begin{array}{c}\text { Aprovados } \\
\text { na UFMG }\end{array}$ \\
\hline Número de indivíduos & 78.068 & 387.863 & 175.851 & 28.763 & 204.614 & 4.674 \\
\hline \multicolumn{7}{|l|}{ Cor ou raça } \\
\hline Brancos & 40,0 & 36,7 & 56,8 & 67,1 & 58,2 & 70,1 \\
\hline Não-brancos & 60,0 & 63,3 & 43,2 & 32,9 & 41,8 & 29,9 \\
\hline \multicolumn{7}{|l|}{ Tipo de escola no EM } \\
\hline Pública & 83,2 & - & N.A. & N.A. & N.A. & 33,0 \\
\hline Privada & 16,8 & - & N.A. & N.A. & N.A. & 67,0 \\
\hline \multicolumn{7}{|l|}{ Renda mensal familiar } \\
\hline Menos de 2 SM & 22,0 & 15,5 & 5,0 & 10,1 & 5,7 & 5,6 \\
\hline 2 a 5 SM & 37,6 & 53,8 & 29,1 & 20,3 & 27,8 & 23,1 \\
\hline 5 a 10 SM & 28,5 & 24,7 & 36,2 & 26,1 & 34,8 & 26,4 \\
\hline 10 a $15 \mathrm{SM}$ & 5,9 & 3,7 & 14,2 & 17,4 & 14,6 & 20,0 \\
\hline 15 a $20 \mathrm{SM}$ & 2,2 & 1,4 & 5,2 & 13,0 & 6,3 & 10,5 \\
\hline 20 a $40 \mathrm{SM}$ & 3,2 & 0,8 & 9,7 & 5,8 & 9,1 & 10,4 \\
\hline Acima de $40 \mathrm{SM}$ & 0,5 & 0,1 & 0,7 & 7,2 & 1,6 & 3,9 \\
\hline \multicolumn{7}{|l|}{ Escolaridade da pessoa de referência } \\
\hline Ensino fundamental incompleto & 43,2 & 46,0 & 22,9 & 12,9 & 21,5 & 11,6 \\
\hline $\begin{array}{l}\text { Ensino fundamental completo ou ensino médio } \\
\text { incompleto }\end{array}$ & 22,6 & 16,3 & 9,1 & 12,9 & 9,6 & 9,4 \\
\hline Ensino médio completo & 20,5 & 33,4 & 28,5 & 28,6 & 28,5 & 28,7 \\
\hline Ensino superior incompleto ou completo & 13,7 & 4,3 & 39,5 & 45,7 & 40,4 & 47,8 \\
\hline
\end{tabular}

Fonte: IBGE. Pesquisa Nacional por Amostra de Domicílios - PNAD 2007. Copeve 2008. Elaboração dos autores.

(1) Compreende os estudantes que estavam cursando o último ano do ensino médio.

(2) Compreende os indíviduos que já concluíram o ensino médio, mas ainda não cursavam ensino superior. 
para o ES e se esse realmente ocorrerá. $\mathrm{Na}$ próxima seção, esse ponto será estudado com a utilização de modelos MQO. Além disso, abordam-se as consequências da aplicação de políticas de bônus adicional na UFMG, ambos estudos baseados nos resultados do Enem de 2005.

\section{Um estudo de caso sobre a aplicação de bônus adicional na UFMG}

Nessa seção, dividida em três partes, discutem-se alguns dos efeitos da aplicação de bônus adicional na UFMG, tendo também como base a recente expansão de vagas no ES público brasileiro via Reuni. Primeiro, são abordadas algumas das variáveis que influenciam no desempenho escolar de estudantes no EM. Em seguida, são realizadas simulações com diferentes políticas de bônus adicional, em que foram analisadas as consequências com relação à distribuição étnica e de renda para os indivíduos que ingressariam na UFMG. Por fim, são estudados os possíveis impactos no potencial de aprendizado do aluno da UFMG em virtude dessas políticas.

\section{Fatores que influenciam o desempenho escolar do ensino médio na $R M B H$}

São diversos os fatores que influenciam o desempenho escolar do estudante no ensino médio e, consequentemente, na nota que um possível candidato obteria no exame vestibular da UFMG. Para analisar esse ponto, foram utilizados os resultados do Enem obtidos tanto nas provas objetivas quanto na redação, como proxi para um resultado potencial nesse exame vestibular. Esse fato se justifica por pelo menos duas razões. $A$ primeira é que o Enem, com modificações a serem futuramente incorporadas, deverá, em breve, ser utilizado como método de seleção nas instituições de ES no Brasil. Além disso, espera-se que o resultado obtido no Enem seja muito correlacionado com o resultado efetiva ou potencialmente alcançado no exame de seleção da UFMG.

O Enem, elaborado pelo Inep e destinado aos alunos que estão concluindo ou já concluíram o ensino médio, avalia as competências e habilidades adquiridas nesse nível de ensino (para mais detalhes ver www.enem.inep.gov.br). Nas análises empreendidas neste trabalho, foram utilizados os microdados do Enem de 2005.

Como demonstrado anteriormente, a maioria dos estudantes que ingressam na UFMG tem como origem algum município da RMBH. O Enem de 2005 para essa região contou com um total de 45.520 inscritos, dos quais 33.132 tiveram resultados positivos nas provas objetivas e na de redação e foram selecionados para as análises posteriores. Entre esses, a maior parte (72,6\%) era proveniente de escolas estaduais, vindo em seguida os oriundos de escolas particulares $(14,3 \%)$, municipais $(11,4 \%)$ e federais $(1,7 \%)$.

Note-se que os inscritos nesse exame constituíram uma seleção positiva entre todos os que poderiam fazer o exame. De forma geral, escolas de melhor qualidade apresentam maiores proporções entre os inscritos no Enem. Além disso, entre os inscritos, os que efetivamente tiveram notas positivas nas duas provas do exame também formam uma seleção com viés positivo. Assim, a seleção da amostra de alunos que efetivamente obtêm nota positiva no Enem é uma amostra não-randomizada, uma vez que não retrata de forma representativa todos os estudantes que terminam o ensino médio. Vários fatores influenciam esse viés positivo de seleção da amostra, incluindo aqueles observáveis, tais como renda domiciliar, escolaridade dos pais, cor/raça, gênero, etc., bem como aspectos não-observáveis, como motivação, esforço, habilidades intrínsecas, etc.

Assim, ao se discutirem os fatores observáveis que impactam no desempenho escolar dos alunos de diferentes escolas, deve-se abordar o problema de autosseleção. Por exemplo, resultados econométricos derivados de amostras com autosseleção que não tratam explicitamente desse viés podem apresentar problemas de estimação. Dessa forma, diferentes métodos de correção são propostos, inclusive o método de dois estágios de Heckman (1979). Entretanto, a autosseleção positiva não traz problemas marcantes para a análise 
específica empreendida aqui, uma vez que os potenciais estudantes no ES também são positivamente selecionados pelos mesmos motivos que influenciam a autosseleção da prova do Enem.

Como proxi para o resultado que seria obtido pelo indivíduo no vestibular da UFMG, foi utilizada uma média ponderada das notas do Enem: a nota da prova objetiva com peso $2 / 3$; e a nota da redação com peso $1 / 3$. Tentou-se, assim, aproximar os assuntos analisados pelo Enem dos pesos observados no exame vestibular. Dessa maneira, os valores da proxi variavam de 0 a 100 e, além disso, tinham uma distribuição aproximadamente normal, com leve assimetria em direção aos valores menores, com média 46,6 e desvio-padrão 13,5. Essa foi a variável dependente utilizada nos modelos MQO.

Como variável independente, foram utilizados fatores que influenciam o desempenho escolar do estudante. A identificação dessas variáveis teve como base a discussão desenvolvida na primeira seção desse texto e também o estudo de Silva e Hasenbalg (2002), que incluem tanto características pessoais quanto informações relativas ao capital econômico, cultural e social do indivíduo. Segue uma breve explicação de cada uma das variáveis incluídas nos seis modelos, cujos resultados são apresentados na Tabela 5.

No primeiro modelo, incluem-se variáveis individuais - idade, sexo e cor - e se o indivíduo trabalhava. A idade é uma importante variável de controle, pois podem existir diferenciais no desempenho escolar que sejam correlacionados com a faixa etária do indivíduo. Essa variável é incluída no seguinte formato: 1 para até 17 anos, 2 para 18, 3 para 19, até 9 para 25 anos e mais. No entanto, a relação entre idade e desempenho escolar pode ser não-linear e, então, incluiu-se um termo quadrático da idade para captar uma possível concavidade nessa relação. Quanto ao sexo, foi incluída uma dummy com os seguintes valores: 1 para o sexo feminino e 0 para o masculino. De forma geral, as mulheres apresentam maior escolaridade do que os homens (BRAGA; PEIXOTO, 2006) e a expectativa inicial é de que o coeficiente seja positivo. Para cor/raça foi também utilizada uma dummy: 1 para brancos/amarelos e 0 para pretos/ pardos/indígenas.

A partir da análise da seção anterior, espera-se que o coeficiente da variável seja positivo, pois indivíduos brancos/amarelos tendem a apresentar maiores níveis de escolaridade, mesmo controlando por efeitos correlacionados às demais variáveis incluídas nos modelos. No modelo 1 foi incluída ainda uma outra variável individual em formato de dummy, indicando se o indivíduo trabalhava ou não (1 para sim e 0 para não).

Os modelos 2 e 3 incluem também fatores familiares que podem impactar no desempenho escolar. A renda domiciliar foi inserida no modelo e se correlaciona com o montante de recursos econômicos disponíveis aos jovens das famílias. Devido à possibilidade de um efeito não-linear dessa variável, foram incluídas cinco dummies indicando a renda: menos de 2 SM, de 2 a $5 \mathrm{SM}$, de 5 a $10 \mathrm{SM}$, de 10 a 30 SM e acima de $30 \mathrm{SM}$. A primeira entre essas categorias foi utilizada como referência nos modelos.

Outro fator que pode influenciar no desempenho escolar é a escolaridade da pessoa de referência no domicílio, uma variável relacionada com o capital cultural e social do ambiente em que o indivíduo está inserido. Essa variável foi incluída no modelo 2 e foi medida em termos de anos de escolaridade completos da pessoa de referência no domicílio. Pelas mesmas razões descritas para renda, foram confeccionadas quatro dummies para a variável, respeitando as transições do sistema de ensino brasileiro e o efeito diploma: até o ensino fundamental incompleto; até o ensino médio incompleto; ensino médio completo; e ensino superior incompleto ou completo. Essa última categoria foi utilizada como referência para as demais nos modelos.

Além disso, como discutido para os demais modelos apresentados na Tabela 5 , aspectos relacionados à escola também podem ser decisivos. O modelo 4 inclui as variáveis individuais presentes no modelo 1 e quatro dummies referentes ao tipo de escola do inscrito no Enem no ensino médio: se estadual, se federal, se municipal ou se 
privada, todas com 1 para sim e 0 para não. A primeira das categorias foi utilizada como referência.

O modelo 5 inclui todas as variáveis presentes nos modelos 3 e 4 . Já o modelo 6 inclui ainda algumas outras dummies, todas com 1 para sim e 0 para não: três indicando se o indivíduo tinha estudado o ensino fundamental em escola pública, em escola privada ou uma parte em cada tipo de escola, sendo a primeira classificação utilizada como referencia; e quatro dummies indicando se o indivíduo tinha cursado o ensino médio no turno diurno, a maior parte no turno diurno, a maior parte no turno noturno ou somente no noturno, sendo que a primeira dessas foi a referência.

Uma vez apresentadas as variáveis independentes, segue a discussão dos resultados. Note-se que todas as variáveis foram significativas em todos os modelos.

A variável idade teve um coeficiente negativo em todos os modelos e essa variável ao quadrado foi positiva em todos eles. Ou seja, a relação da nota com a idade é decrescente e convexa. Assim, indivíduos mais jovens tendem a ter uma nota maior e a diferença entre as idades tende a diminuir com o aumento da mesma.

No modelo 1, a dummy de sexo foi negativa, indicando que as mulheres, quando controlados os efeitos das demais variáveis do modelo, tinham um resultado inferior em aproximadamente três pontos em comparação aos homens. Observe-se, ainda, que em todos os modelos o coeficiente foi negativo e variava entre $-3,06$ e $-1,68$. Isso parece contradizer os resultados esperados, uma vez que, de forma geral, as mulheres no Brasil têm melhores níveis educacionais. Entretanto, esse resultado em favor dos homens é afetado pela ponderação utilizada na proxi referente à nota no vestibular. Em geral, homens apresentam melhores resultados na prova objetiva e mulheres, na prova de redação. Assim, caso a proxi utilizada fosse uma média simples das notas do Enem, o resultado seria distinto e mais favorável às mulheres. Além disso, o maior diferencial entre os sexos é observado até a conclusão do ensino médio. Ou seja, já que apenas os que concluem esse nível de ensino estão entre os inscritos no Enem, esses diferenciais não são captados pelos modelos MQO. Além disso, como salientado anteriormente, entre os concluintes do ensino médio, os que efetivamente tinham notas positivas no Enem constituíam uma seleção positiva e não podem ser considerados representativos de toda a população.

Note-se, ainda, que os homens tendem a participar mais do mercado de trabalho e também, em parte devido a essa maior participação na População Economicamente Ativa (PEA), são em média mais velhos do que as mulheres. Esses dois fatores impactam negativamente no desempenho escolar, como poder ser observado pelos coeficientes negativos da variável idade e da dummy de trabalha.

A dummy de cor teve um coeficiente positivo em todos os modelos, indicando que brancos/amarelos obtinham resultados melhores no Enem. Entretanto, o valor do coeficiente no modelo 1 foi superior a 4, enquanto no modelo 6 correspondeu a apenas 0,68 . Isto é, a diferença entre etnias, uma vez controlados os efeitos das demais variáveis, é pequena, menos de 1 ponto, apesar de significativa. Ou seja, outros fatores incluídos nos modelos explicam em grande medida os diferenciais entre esses grupos.

A última das variáveis individuais mostrou que pessoas que trabalhavam tendiam a ter notas menores, mesmo controlando pelos demais fatores. Todavia, assim como observado para cor, a diferença diminui com o aumento do número de variáveis independentes e no modelo 6 era pequena, menor que 1 ponto, mesmo que significativa.

O modelo 2 inclui também as dummies de renda familiar. Verifica-se que todas as dummies foram positivas e significativas, indicando que, com o aumento da renda, as notas no Enem tendiam a aumentar. Entretanto, observa-se que até $5 \mathrm{SM}$ a diferença não é tão marcante (aproximadamente 4 pontos) e, a partir de $10 \mathrm{SM}$, os diferenciais tendem a se estabilizar próximos de 20 pontos. Verifica-se que grande parte dos diferenciais devido à cor e a inserção no mercado de trabalho diminuem com a inclusão das dummies de renda. 
O modelo 3 inclui também as dummies de escolaridade da mãe. Todos os coeficientes foram positivos e significativos. Note-se que os coeficientes de renda familiar, mesmo tendo diminuído, continuaram positivos e significativos. Assim, mesmo controlando pela renda, a influência da escolaridade da mãe é marcante e próxima de 10 pontos para o ES incompleto ou completo.

O modelo 4 inclui somente as variáveis individuais e as relacionadas ao tipo de escola. $\mathrm{O}$ objetivo é retirar os efeitos de renda familiar e escolaridade da mãe dessa análise inicial. Indivíduos originados ou que estudavam em escolas federais tinham um resultado 26 pontos acima daqueles ligados às escolas estaduais, mesmo controlando pelos atributos individuais. Para as escolas particulares, essa diferença era de 17 pontos. Escolas municipais e estaduais diferenciam em pouco mais de 1 ponto em favor das primeiras, com resultados muito similares entre elas. Ou seja, escolas federais e particulares tinham resultados muito superiores às demais.

O modelo 5 inclui também as variáveis de renda familiar e escolaridade da mãe. Observe-se que os coeficientes de renda e escolaridade da mãe diminuem um pouco, uma vez que são correlacionados com o tipo de escola frequentado pelo aluno, mas ainda assim continuam significativos e com grande magnitude. Deve-se ressaltar que, mesmo controlando pelas variáveis socioeconômicas, indivíduos de escolas privadas tinham um resultado 10 pontos superiores aos da rede estadual e os de escola federal apresentaram diferencial de mais de 20. Isto indica que existem outros fatores relacionados ao tipo de escola, distintos do nível de renda ou escolaridade da mãe, que impactam de forma marcante no desempenho escolar.

O último dos modelos inclui todas as variáveis do modelo 5 e outras sete dummies referentes ao ensino fundamental e ao turno do ensino médio. Mesmo controlando por todos esses efeitos, pessoas mais jovens, do sexo masculino e que não trabalhavam tinham notas superiores. O diferencial entre os grupos de cor era de apenas 0,68 , mas significativo. A renda familiar, mesmo na faixa de 2 a 5 SM, tinha um impacto maior do que esse, acima de 2 pontos. Note-se, ainda que o coeficiente para uma renda acima de $10 \mathrm{SM}$ era superior a 6 pontos, indicando que a renda impactava de maneira decisiva nos diferenciais educacionais. Mesmo controlando pela renda e outros fatores, a escolaridade da mãe tinha grande influência nas notas, principalmente a partir do ensino médio completo, acima de 2,5.

Quanto ao tipo de escola no ensino médio, a diferença entre as escolas federais e estaduais era de mais de 20 pontos. Ou seja, os universos de escolas públicas federais são muito diferentes das demais escolas públicas em fatores não captados pelas variáveis incluídas nos modelos. A diferença entre as escolas particulares e estaduais era de mais de 7 pontos, muito inferior ao observado na comparação anterior, uma vez que grande parte dos diferenciais entre escolas privadas e estaduais/municipais relacionase ao nível socioeconômico.

O modelo 6 inclui ainda as duas dummies referentes ao local onde o indivíduo tinha estudado no ensino fundamental. Note-se que ambas - tanto somente uma parte como todo ele cursado na rede privada - foram positivas, sugerindo a importância da formação fundamental nos resultados do Enem e indicando, como proposto no PDE, que o ensino seja abordado em uma perspectiva integrada. Verifica-se que, com a inclusão dessas últimas dummies, ocorre uma diminuição nos coeficientes socioeconômicos e com relação ao tipo de escola no ensino médio, mostrando a correlação positiva entre as variáveis.

Por fim, o turno no qual foi feito o ensino médio teve pequeno impacto nas notas, sempre menor que 2 pontos. Note-se que, uma vez controlados os demais efeitos, estudar somente no turno diurno não apresentava resultados maiores do que em todas as demais possibilidades.

Como conclusão final sobre esses modelos, pode-se inferir que são múltiplos os fatores que impactam na nota do indivíduo no Enem e, portanto, em sua possibilidade de inserção no ES público. Entre esses aparecem a cor/raça do indivíduo, a renda familiar, a escolaridade da mãe e os efeitos 
TABELA 5

Análise dos fatores que impactam na nota do Enem via modelos MQO Região Metropolitana de Belo Horizonte - 2005

\begin{tabular}{|c|c|c|c|c|c|c|}
\hline Variáveis & Modelo 1 & Modelo 2 & Modelo 3 & Modelo 4 & Modelo 5 & Modelo 6 \\
\hline Constante & 57,3 & 52,2 & 49,7 & 52,5 & 49,3 & 47,5 \\
\hline Idade & $-6,17$ & $-4,91$ & $-4,47$ & $-4,88$ & $-4,32$ & $-3,91$ \\
\hline Idade ao quadrado & 0,44 & 0,35 & 0,34 & 0,34 & 0,32 & 0,30 \\
\hline Sexo & $-3,06$ & $-1,87$ & $-1,77$ & $-2,23$ & $-1,68$ & $-1,82$ \\
\hline Cor & 4,37 & 1,96 & 1,31 & 1,77 & 0,84 & 0,68 \\
\hline Trabalha & $-4,18$ & $-2,55$ & $-2,08$ & $-1,78$ & $-1,32$ & $-0,69$ \\
\hline \multicolumn{7}{|l|}{ Renda familiar } \\
\hline De 2 a 5 SM & - & 3,97 & 2,97 & - & 2,42 & 2,19 \\
\hline De 5 a 10 SM & - & 10,2 & 7,20 & - & 3,93 & 3,22 \\
\hline De 10 a 30 SM & - & 20,1 & 14,7 & - & 8,21 & 6,69 \\
\hline Acima de 30 SM & - & 22,7 & 16,7 & - & 9,91 & 7,93 \\
\hline \multicolumn{7}{|l|}{ Escolaridade da mãe } \\
\hline Até ensino médio incompleto & - & - & 1,46 & - & 1,19 & 0,93 \\
\hline Ensino médio completo & - & - & 4,73 & - & 3,28 & 2,58 \\
\hline Ensino superior incompleto e completo & - & - & 9,51 & - & 6,21 & 4,89 \\
\hline \multicolumn{7}{|l|}{ Escola } \\
\hline Federal & - & - & - & 26,0 & 22,2 & 20,7 \\
\hline Municipal & - & - & - & 1,41 & 1,12 & 1,47 \\
\hline Privada & - & - & - & 17,0 & 10,7 & 7,70 \\
\hline \multicolumn{7}{|l|}{ Ensino fundamental } \\
\hline Parte pública, parte privada & - & - & - & - & - & 2,09 \\
\hline Somente privada & - & - & - & - & - & 5,71 \\
\hline \multicolumn{7}{|l|}{ Turno } \\
\hline Maior parte diurno & - & - & - & - & - & $-1,52$ \\
\hline Maior parte noturno & - & - & - & - & - & 1,83 \\
\hline Somente noturno & - & - & - & - & - & 1,09 \\
\hline R2 ajustado & 0,05 & 0,17 & 0,20 & 0,37 & 0,41 & 0,43 \\
\hline Número de observações & 31132 & 31132 & 31132 & 31132 & 31132 & 31132 \\
\hline
\end{tabular}

Fonte: Enem 2005.

da menor qualidade das escolas estaduais e municipais. Como todos esses fatores são inter-relacionados, indivíduos não-brancos tendem a ser excluídos não por causa de um deles especificamente, mas pela interação de todos eles. Uma comparação entre os modelos 1 e 6 indica que fatores socioeconômicos explicam a maior parte dos diferenciais entre os grupos de cor/ raça, mas não tudo. Uma diferença residual permanece mesmo com a inclusão de todas as variáveis do modelo 6 .

\section{Simulações de políticas de bônus adicional}

Os modelos econométricos indicaram alguns dos fatores que influenciam no desempenho escolar do estudante, em parti- cular a cor do indivíduo e o tipo de escola cursada no ensino médio. Nessa seção são apresentadas algumas simulações com relação à implementação de políticas de bônus adicional na UFMG que tratam dessas variáveis.

Para tanto, deve-se, inicialmente, fazer um paralelo entre as notas da proxi utilizada aqui e as notas potenciais no vestibular da UFMG. A Tabela 6 compara alguns dados dos aprovados nessa instituição, como descrito na base de dados da Copeve, com os dados do Enem, segundo cor/raça, tipo de escola, renda familiar e escolaridade da pessoa de referência. Dada a diferença de qualidade de ensino entre as escolas federais e as demais públicas, como apresentado anteriormente, essas primeiras são descritas também em separado. 
O objetivo é definir uma nota da proxi utilizada nesse trabalho, de forma a obter uma composição discente como retratado pelo Enem mais próxima possível dos realmente aprovados na UFMG. Para tanto, foram consideradas diferentes notas de corte na proxi utilizada.

Tomando como base a distribuição étnica, a nota de corte para entrar na UFMG seria entre 75 e 80 pontos na proxi utilizada. Para as redes pública e privada, teríamos uma nota de corte entre 70 e 75 pontos. Entretanto, note-se que as escolas federais, embora contassem com aproximadamente 50 vezes menos inscritos no Enem do que as estaduais na $\mathrm{RMBH}$, responderiam por metade dos aprovados da rede pública. Tomando como base a distribuição de renda, a nota de corte giraria em torno de 75 pontos e, fazendo o mesmo com a escolaridade da pessoa de referência, ficaria próxima de 70 .
Essa discussão sinalizou que a proxi com as notas do Enem ficaria em torno de 70 a 75 pontos para que os indivíduos aprovados na UFMG fossem semelhantes, nos vários aspectos, aos grupos de pessoas do Enem. Partindo disso e sabendo que existem cursos mais concorridos do que outros na UFMG, optou-se por utilizar duas notas de corte distintas (uma acima e outra abaixo desses valores), que seriam a média geral. A nota 60 foi escolhida como de corte para os cursos menos concorridos, pois o número de indivíduos com nota do Enem acima desse valor é superior ao número de aprovados na UFMG. Isso se justifica porque muitos, entre esses que têm nota superior a 60 no Enem, fariam vestibular para cursos mais concorridos e não seriam aprovados na UFMG. Assim, julgou-se que essa nota retrataria com uma aproximada fidedignidade os cursos menos concorridos. Já a nota

TABELA 6

Aprovados na UFMG, inscritos no Enem que obtiveram notas positivas nas provas objetivas e na redação $e$ aqueles que alcançaram notas entre mais de 60 e mais de 90 , segundo características sociodemográficas Região Metropolitana de Belo Horizonte

Em porcentagem

\begin{tabular}{|c|c|c|c|c|c|c|c|}
\hline \multirow{2}{*}{ Características sociodemográficas } & \multirow{2}{*}{$\begin{array}{l}\text { Aprovados } \\
\text { na UFMG }\end{array}$} & \multirow{2}{*}{$\begin{array}{l}\text { Inscritos } \\
\text { no Enem } \\
\text { com notas } \\
\text { positivas }\end{array}$} & \multicolumn{5}{|c|}{ Nota do Enem acima de } \\
\hline & & & 60 & 70 & 75 & 80 & 90 \\
\hline Número de indivíduos & 4.674 & 33.132 & 5.543 & 2.385 & 1.312 & 619 & 226 \\
\hline \multicolumn{8}{|l|}{ Cor ou raça } \\
\hline Brancos & 70,1 & 39,2 & 57,8 & 64,7 & 66,7 & 70,8 & 71,0 \\
\hline Não-brancos & 29,9 & 60,8 & 42,2 & 35,3 & 33,3 & 29,2 & 29,0 \\
\hline \multicolumn{8}{|l|}{ Tipo de escola no EM } \\
\hline Pública & 33,0 & 85,7 & 50,0 & 34,3 & 28,5 & 24,2 & 20,8 \\
\hline Federal & - & 1,7 & 8,9 & 14,9 & 17,2 & 18,9 & 17,7 \\
\hline Privada & 67,0 & 14,3 & 50,0 & 65,7 & 71,5 & 75,8 & 79,2 \\
\hline \multicolumn{8}{|l|}{ Renda mensal familiar } \\
\hline Menos de 2 SM & 5,6 & 44,9 & 15,1 & 8,0 & 5,9 & 3,4 & 2,9 \\
\hline 2 a 5 SM & 23,1 & 37,1 & 33,0 & 24,0 & 19,6 & 17,2 & 11,5 \\
\hline 5 a $10 \mathrm{SM}$ & 26,4 & 11,0 & 23,0 & 25,1 & 23,8 & 23,5 & 25,5 \\
\hline Acima de 10 SM & 44,8 & 7,1 & 28,9 & 42,9 & 50,7 & 55,8 & 60,1 \\
\hline \multicolumn{8}{|l|}{ Escolaridade da pessoa de referência } \\
\hline Até EM incompleto & 21,0 & 70,1 & 30,1 & 18,0 & 13,8 & 11,0 & 8,5 \\
\hline EM completo & 28,7 & 17,7 & 28,3 & 26,1 & 22,9 & 21,3 & 18,5 \\
\hline ES incompleto e completo & 47,8 & 12,3 & 41,6 & 55,9 & 63,3 & 67,7 & 73,0 \\
\hline
\end{tabular}

Fonte: Enem 2005. Copeve 2008. 
80 foi escolhida como corte para os cursos mais concorridos por englobar um grupo populacional com os indicadores sociais mais elitizados do que os aprovados na UFMG. Além disso, o número de indivíduos (619) foi julgado razoável para espelhar os melhores colocados de todos os cursos e mais aqueles que efetivamente passaram em cursos mais concorridos, como Medicina, Engenharia Química e Ciências Biológicas diurno.

Foram feitas cinco simulações de políticas de bônus adicional que são semeIhantes àquelas efetivamente adotadas nas instituições de nível superior no Brasil. As notas no Enem das pessoas de cor preta/ parda/indígena foram aumentadas em $5 \%$, na primeira simulação, e em $10 \%$, na segunda. Na terceira, as notas dos estudantes da rede pública foram aumentadas em $10 \%$. Dada a grande disparidade entre as escolas federais e as demais públicas, na simulação 4, somente as notas das pessoas das escolas estaduais e municipais foram aumentadas em 10\%. A simulação 5 aumenta ainda em $5 \%$ as notas das pessoas de cor preta/parda/indígena. Note-se que as demais notas não foram alteradas e, portanto, mais pessoas seriam aprovadas no vestibular, o que segue a política de expansão do ES via Reuni.

A Tabela 7 mostra os resultados dessas simulações com relação à proporção de não-brancos e a de estudantes originados dos diferentes tipos de escola, para os cursos mais e os menos concorridos. Quando comparados com os dados originais do Enem, como mostra os resultados para a simulação $1 \mathrm{com}$ aumento de $5 \%$ nas notas dos não-brancos, a proporção desse grupo de cor, nos cursos menos concorridos, passaria de $42,2 \%$ para $49,6 \%$ e, nos mais concorridos, a mudança seria ainda maior, de $29,2 \%$ para $46,0 \%$. Observa-se que também ocorre aumento na proporção de pessoas originadas das escolas estaduais e municipais.

Na segunda simulação, que incrementa em $10 \%$ as notas dos não-brancos, as variações, de forma geral, são semelhantes, mas ainda maiores do que as verificadas na primeira simulação.
A terceira simulação aumenta em 10\% a nota dos estudantes oriundos das escolas públicas, não fazendo qualquer alteração com relação à cor. Comparando com a primeira simulação, note-se que o impacto quanto à proporção dos não-brancos nos cursos menos e mais concorridos seria inferior. Além disso, a proporção de estudantes oriundos da rede pública, inclusive das escolas estaduais e municipais, aumentaria muito. Porém, muitos dos beneficiados, principalmente nos cursos mais concorridos, seriam os estudantes das escolas federais, que, como visto anteriormente, frequentam escolas de boa qualidade e já apresentam maiores probabilidades de ingressarem no ES. Cabe aqui uma ressalva se esses deveriam ser beneficiados pelas políticas de bônus adicional ou não.

Assim, a quarta simulação aumenta a nota apenas dos indivíduos das redes estaduais e municipais. As diferenças com relação à cor entre as simulações 3 e 4 são pequenas. A principal diferença é verificada quanto ao tipo de escola frequentada, principalmente nos cursos mais concorridos, com grande aumento dos estudantes das redes estadual e municipal, sendo que o contrário ocorreria para os estudantes da rede federal. Ainda assim, esses últimos apresentariam uma proporção entre os aprovados muito superior àquela de estudantes nessa rede de ensino na RMBH.

Por fim, a simulação 5 aumenta em 5\% a nota dos não-brancos e em $10 \%$ a dos originados das escolas estaduais e municipais. Observa-se que os não-brancos seriam maioria tanto nos cursos menos como nos mais concorridos. Ou seja, os grupos desfavorecidos seriam sobrerrepresentados. Comparando-se os resultados da simulação 5 com aqueles do Enem, nota-se que a participação das escolas estaduais e municipais aumentaria em $50 \%$ nos cursos menos concorridos, passando de $41,7 \%$ para mais de $60 \%$, e em $600 \%$ nos mais concorridos, passando de $5,4 \%$ para $35,2 \%$. Como esses últimos cursos estão entre os que mais promovem a mobilidade social, isso teria um grande impacto na quebra da transmissão intergeneracional de posições socialmente desfavoráveis em termos socioeconômicos. 
TABELA 7

Proporção de não-brancos e de estudantes das escolas públicas que obtiveram as notas de corte no Enem (1) para os cursos menos e mais concorridos, segundo simulações de implementação de políticas de bônus adicional na UFMG

Em porcentagem

\begin{tabular}{|c|c|c|c|c|c|c|c|c|}
\hline \multirow[b]{2}{*}{ Simulações } & \multicolumn{4}{|c|}{ Cursos menos concorridos } & \multicolumn{4}{|c|}{ Cursos mais concorridos } \\
\hline & $\begin{array}{c}\text { Não- } \\
\text { brancos }\end{array}$ & $\begin{array}{l}\text { Escolas } \\
\text { públicas }\end{array}$ & $\begin{array}{l}\text { Escolas } \\
\text { federais }\end{array}$ & $\begin{array}{c}\text { Escolas } \\
\text { estaduais e } \\
\text { municipais }\end{array}$ & $\begin{array}{c}\text { Não- } \\
\text { brancos }\end{array}$ & $\begin{array}{l}\text { Escolas } \\
\text { públicas }\end{array}$ & $\begin{array}{l}\text { Escolas } \\
\text { federais }\end{array}$ & $\begin{array}{l}\text { Escolas } \\
\text { estaduais e } \\
\text { municipais }\end{array}$ \\
\hline Enem(1) & 42,2 & 49,2 & 7,5 & 41,7 & 29,2 & 21,9 & 16,5 & 5,4 \\
\hline Simulação 1 & 49,6 & 53,3 & 6,7 & 46,6 & 46,0 & 26,3 & 17,5 & 8,8 \\
\hline Simulação 2 & 54,9 & 56,8 & 6,1 & 50,8 & 58,5 & 32,2 & 16,8 & 15,4 \\
\hline Simulação 3 & 47,9 & 63,7 & 6,8 & 56,9 & 38,3 & 54,1 & 28,3 & 25,8 \\
\hline Simulação 4 & 47,8 & 63,6 & 6,5 & 57,1 & 36,2 & 44,8 & 13,8 & 31,0 \\
\hline Simulação 5 & 53,6 & 65,3 & 5,0 & 60,3 & 52,0 & 47,6 & 12,4 & 35,2 \\
\hline
\end{tabular}

Fonte: Enem 2005.

(1) As notas de corte do Enem corresponderam a 60, para os cursos menos concorridos, e a 80, para os mais concorridos. Nota: Simulação 1 = aumento de $5 \%$ na nota de não-brancos.

Simulação 2 = aumento de $10 \%$ na nota de não-brancos.

Simulação 3 = aumento de $10 \%$ na nota dos estudantes oriundos de escolas públicas.

Simulação 4 = aumento de $10 \%$ na nota dos estudantes oriundos somente das escolas públicas estaduais e municipais.

Simulação 5 = aumento de $5 \%$ na nota de não-brancos e de $10 \%$ na nota dos estudantes oriundos das escolas públicas estaduais e municipais.

A Tabela 8 mostra a distribuição de nãobrancos e brancos nas cinco simulações, segundo faixas de renda e cursos menos e mais concorridos. Note-se que para a simulação 1 haveria um aumento na participação dos indivíduos com renda familiar de até 2 SM entre os não-brancos, principalmente de forma relativa nos cursos mais concorridos. Como as notas dos brancos não foram incrementadas, não ocorrem mudanças para esse grupo. A simulação 2 amplifica esses resultados. Observa-se que a participação de não-brancos com renda de até $2 \mathrm{SM}$ aumenta de $3,2 \%$ para $11,4 \%$ nos cursos mais concorridos.

A simulação 3 altera as notas dos estudantes oriundos da escola pública sem qualquer distinção de cor. O impacto nas populações não-brancas é menor do que nas simulações anteriores para indivíduos com renda acima de $5 \mathrm{SM}$, mas o contrário ocorre para as pessoas com rendas inferiores a esse patamar. Esse mesmo fato é observado com relação aos diferenciais por renda para brancos. Ou seja, se, por um lado, o aumento de pretos e pardos seria menor em algumas faixas de renda, por outro, haveria maior inclusão das classes mais desfavorecidas em termos de renda, indicando diferentes escolhas na forma de inserção. Os resultados da quarta e quinta simulações são muito similares aos da terceira em relação à distribuição de renda.

As diferentes políticas discutidas apresentam distintos impactos positivos e negativos do ponto de vista tanto social quanto étnico. Resta saber se essas políticas não teriam uma influência negativa na qualidade potencial do corpo discente da UFMG. Esse é o último tema tratado a seguir.

Consequências da política de bônus adicional quanto às características dos alunos

Com a política de bônus adicional, alunos que não entrariam na UFMG passam a ingressar nessa instituição. Uma das grandes preocupações com relação a esses alunos é se eles terão potencial de se desenvolverem similar aos alunos que ingressam na UFMG via vestibular sem bônus adicional, mesmo tendo obtido um nível de aprendizagem inferior até o fim do ensino médio, uma vez que as ações afirmativas não devem afetar a excelência de ensino da instituição.

Existem vários atributos do indivíduo que o fazem ser um candidato a bom estudante no ES, mesmo partindo de uma base mais fraca, em um processo de "catching-up". O 
TABELA 8

Distribuição dos indivíduos que obtiveram as notas de corte do Enem para os cursos menos e mais concorridos da UFMG, por simulação, segundo cor/raça e renda familiar

Em porcentagem

\begin{tabular}{|c|c|c|c|c|c|c|c|}
\hline \multirow{2}{*}{ Cor/raça } & \multirow{2}{*}{ Renda familiar } & Enem & $\begin{array}{c}\text { Simulação } \\
1\end{array}$ & $\begin{array}{c}\text { Simulação } \\
2\end{array}$ & $\begin{array}{c}\text { Simulação } \\
3\end{array}$ & $\begin{array}{c}\text { Simulação } \\
4\end{array}$ & $\begin{array}{c}\text { Simulação } \\
5\end{array}$ \\
\hline & & \multicolumn{6}{|c|}{ Cursos menos concorridos } \\
\hline \multirow[t]{4}{*}{ Não-brancos } & Menos de $2 \mathrm{SM}$ & 21,6 & 25,0 & 27,3 & 28,8 & 28,7 & 29,8 \\
\hline & 2 a 5 SM & 40,5 & 41,6 & 42,4 & 42,9 & 42,9 & 44,1 \\
\hline & 5 a $10 \mathrm{SM}$ & 21,3 & 19,7 & 18,6 & 17,4 & 17,4 & 16,3 \\
\hline & Acima de $10 \mathrm{SM}$ & 16,5 & 13,8 & 11,6 & 10,9 & 11,0 & 9,8 \\
\hline \multirow[t]{5}{*}{ Brancos } & Menos de 2 SM & 10,2 & 10,2 & 10,2 & 15,0 & 15,0 & 15,0 \\
\hline & 2 a 5 SM & 27,5 & 27,5 & 27,5 & 31,8 & 31,8 & 31,8 \\
\hline & 5 a 10 SM & 24,2 & 24,2 & 24,2 & 22,2 & 22,2 & 22,2 \\
\hline & Acima de 10 SM & 38,0 & 38,0 & 38,0 & 31,0 & 31,1 & 31,1 \\
\hline & & \multicolumn{6}{|c|}{ Cursos mais concorridos } \\
\hline \multirow[t]{4}{*}{ Não-brancos } & Menos de 2 SM & 3,2 & 8,2 & 11,4 & 12,5 & 13,5 & 14,6 \\
\hline & 2 a 5 SM & 25,9 & 24,6 & 28,6 & 37,0 & 36,7 & 35,2 \\
\hline & 5 a 10 SM & 27,8 & 26,4 & 27,7 & 26,2 & 23,6 & 23,2 \\
\hline & Acima de 10 SM & 43,0 & 40,7 & 32,4 & 24,2 & 26,2 & 27,0 \\
\hline \multirow[t]{4}{*}{ Brancos } & Menos de 2 SM & 3,3 & 3,3 & 3,3 & 6,5 & 6,1 & 6,1 \\
\hline & 2 a 5 SM & 13,6 & 13,6 & 13,6 & 24,7 & 22,7 & 22,7 \\
\hline & 5 a 10 SM & 22,1 & 22,1 & 22,1 & 22,7 & 21,3 & 21,3 \\
\hline & Acima de $10 \mathrm{SM}$ & 61,0 & 61,0 & 61,0 & 46,0 & 49,9 & 49,9 \\
\hline
\end{tabular}

Fonte: Enem 2005.

(1) As notas de corte do Enem corresponderam a 60, para os cursos menos concorridos, e a 80, para os mais concorridos. Nota: Simulação 1 = aumento de $5 \%$ na nota de não-brancos.

Simulação 2 = aumento de $10 \%$ na nota de não-brancos.

Simulação 3 = aumento de $10 \%$ na nota dos estudantes oriundos de escolas públicas.

Simulação 4 = aumento de $10 \%$ na nota dos estudantes oriundos somente das escolas públicas estaduais e municipais.

Simulação 5 = aumento de $5 \%$ na nota de não-brancos e de $10 \%$ na nota dos estudantes oriundos das escolas públicas estaduais e municipais.

Enem apresenta uma série de quesitos sobre a pessoa, que podem estar relacionados ao seu potencial de aprendizado, dos quais foram selecionados dez. Como muitos desses quesitos podem ser fortemente correlacionadas, foi aplicada a análise fatorial, agrupandoos em cinco componentes:

- componente 1 - Interesse por economia e política;

- componente 2 - Interesse por cultura, meio ambiente e questões sociais;

- componente 3 - Hábito de leitura de jornais e revista;

- componente 4-Conhecimento de idioma estrangeiro;

- componente 5 - Hábito de leitura de livros.
Foi feita a média dos valores de cada uma das questões para cada um dos componentes.

Para determinar a relação entre a nota da proxi para o vestibular e esses componentes, inicialmente essa primeira foi considerada a variável dependente e os últimos foram incluídos como variáveis independentes em um modelo MQO. Os resultados são mostrados na Tabela 9. Todos os coeficientes foram significativos, sendo que quatro apresentaram coeficientes positivos e somente o componente 3 - hábito de leitura de jornais e revista - obteve valor negativo. Ou seja, as componentes referentes a interesse por economia e política, interesse por cultura, meio ambiente e questões sociais, conhecimento de idioma estrangeiro e hábito de leitura de livros 
eram positivamente correlacionadas com o desempenho escolar.

Como forma de complementação dos resultados, compararam-se os valores médios para cada um desses componentes entre os indivíduos que seriam aprovados em cursos menos e mais concorridos, segundo os dados do Enem, e os demais que não seriam aprovados nesses cursos (Tabela 10). Entre os cinco componentes, os não-aprovados, tanto para cursos menos como para os mais concorridos, tinham valores significativamente menores em quatro deles, que são justamente os mesmos da análise anterior.

Essas duas análises sugerem que os componentes citados apresentam relação positiva com as notas dos estudantes e assim, de forma aproximada, se relacionam com o desempenho escolar do aluno e, de maneira indireta, com seu potencial de aprendizado.

$\mathrm{Na}$ análise seguinte são comparados os indivíduos que seriam aprovados em cursos menos concorridos (aproximadamente 5.000), tendo as notas do Enem como proxi, e os que seriam beneficiados pelas políticas de bônus adicional discutidas anteriormente, número que varia entre aproximadamente 740 , para a simulação 1 , até 2.730 , para a simulação 5 , ou seja, aqueles indivíduos que entrariam na UFMG por causa dessas políticas (Tabela 11). Observa-se que, nas simulações 1 e 2, o valor do componente 1 para os novos ingressantes na UFMG é maior do que para o grupo controle, ocorrendo o inverso com relação ao componente 4. Ou seja, mesmo tendo uma nota menor no Enem, esses estudantes que teriam o bônus adicional apresentam maior interesse

TABELA 9

Relação entre os componentes da análise fatorial e a nota no Enem

\begin{tabular}{lc}
\hline \multicolumn{1}{c}{ Variáveis } & Coeficientes \\
\hline Constante & 40,51 \\
Componente 1 - Interesse por economia e política & 5,56 \\
Componente 2 - Interesse por cultura, meio ambiente e questões sociais & 2,44 \\
Componente 3 - Hábito de leitura de jornais e revistas & $-3,13$ \\
Componente 4 - Conhecimento de idioma estrangeiro & 12,51 \\
Componente 5 - Hábito de leitura de livros & 1,00 \\
$\mathrm{R}^{2}$ ajustado & 0,074 \\
Número de observações & 31.132 \\
\hline
\end{tabular}

Fonte: Enem 2005.

TABELA 10

Comparação entre os valores médios dos componentes em diferentes grupos para os aprovados e não-aprovados nos cursos menos e mais concorridos da Universidade Federal de Minas Gerais

\begin{tabular}{|c|c|c|c|c|}
\hline \multirow{2}{*}{ Componentes } & \multicolumn{2}{|c|}{ Cursos menos concorridos } & \multicolumn{2}{|c|}{ Cursos mais concorridos } \\
\hline & Aprovados & $\begin{array}{c}\text { Não } \\
\text { aprovados }\end{array}$ & Aprovados & $\begin{array}{c}\text { Não } \\
\text { aprovados }\end{array}$ \\
\hline 1 - Interesse por economia e política & 0,71 & 0,67 & 0,70 & 0,68 \\
\hline 2 - Interesse por cultura, meio ambiente e questões sociais & 0,81 & 0,79 & 0,82 & 0,80 \\
\hline 3 - Hábito de leitura de jornais e revistas & 0,56 & 0,57 & 0,58 & 0,57 \\
\hline 4 - Conhecimento de idioma estrangeiro & 0,42 & 0,11 & 0,69 & 0,15 \\
\hline 5 - Hábito de leitura de livros & 0,56 & 0,53 & 0,61 & 0,53 \\
\hline Número de observações (aproximado) & 5.000 & 24.500 & 555 & 29.000 \\
\hline
\end{tabular}

Fonte: Enem 2005

Nota: Valores em negrito têm diferenças significativas. 
por economia e política do que os que seriam aprovados caso o bônus adicional não existisse. Como esse fator é correlacionado ao desempenho escolar, isso sugere que os estudantes beneficiados têm potencial pelo menos similar ao grupo controle com relação a esse quesito. Entretanto, no que se refere ao conhecimento de idioma estrangeiro, os que seriam abrangidos pelo sistema de bônus adicional têm valores muito inferiores, indicando que esse ponto seria um fator negativo quanto à absorção de conhecimentos em geral. Deve-se ressaltar que esse componente tende a ser fortemente correlacionado com os níveis socioeconômicos do indivíduo.

As três outras simulações ampliam as notas de indivíduos originados em escolas públicas. Além das diferenças já apontadas, os estudantes beneficiados pelo bônus teriam maior interesse por cultura, meio ambiente e questões sociais, fator também positivamente correlacionado com o desempenho escolar. Tal resultado indica que esses novos estudantes, que significam um grande acréscimo no corpo discente da UFMG, apresentariam dois pontos positivos quanto ao potencial de absorção de novos conhecimentos e um negativo, referente à língua estrangeira e aos fatores correlacionados com esse ponto. Assim, caso haja políticas complementares por parte da UFMG com relação ao ensino de idiomas estrangeiros, em conjunto com uma assistência monetária para a permanência do aluno no ES, bem como a pontos diretamente relacionados ao nível socioeconômico prévio do indivíduo, como a menor carga cultural transmitida intergeneracionalmente, os novos alunos, apesar das notas inferiores no Enem, parecem ter um potencial relativamente elevado quanto à absorção de conhecimentos no ES.

\section{Conclusão}

Buchmann e Hannum (2001) ressaltam a necessidade de adaptação dos métodos de pesquisas às realidades mais pobres, agregando dados e fatores diferentes dos países desenvolvidos, mas que geram análises mais realísticas da situação em países em desenvolvimento. Isso seria fundamental para o sucesso das pesquisas que objetivam sugerir mudanças no sistema educacional, de forma a minimizar a exclusão de grupos de desfavorecidos do sistema. Esse trabaIho procura traçar essa linha de raciocínio, buscando os fatores relacionados à escolaridade que são mais expressivos para a realidade brasileira.

Esse estudo mostrou o perfil dos indivíduos aptos a frequentarem o ES da RMBH, dos estudantes universitários da região e dos aprovados no vestibular da UFMG, mapeando a distribuição entre grupos de cor e

TABELA 11

Comparação entre os valores médios dos componentes em diferentes grupos, por simulação

\begin{tabular}{lcccccc}
\hline \multicolumn{1}{c}{ Componentes } & \multirow{6}{c}{ Enem } & \multicolumn{5}{c}{ Simulação } \\
\cline { 3 - 7 } & & $\mathbf{1}$ & $\mathbf{2}$ & $\mathbf{3}$ & $\mathbf{4}$ & $\mathbf{5}$ \\
\hline 1- Interesse por economia e política & $\mathbf{0 , 7 0 5}$ & $\mathbf{0 , 7 3 8}$ & $\mathbf{0 , 7 3 2}$ & $\mathbf{0 , 7 3 3}$ & $\mathbf{0 , 7 3 3}$ & $\mathbf{0 , 7 2 5}$ \\
2 - Interesse por cultura, meio ambiente e questões sociais & 0,812 & 0,817 & 0,818 & $\mathbf{0 , 8 2 3}$ & $\mathbf{0 , 8 2 3}$ & $\mathbf{0 , 8 2 1}$ \\
3- Hábito de leitura de jornais e revista & 0,563 & 0,573 & 0,570 & 0,561 & 0,560 & 0,560 \\
4- Conhecimento de idioma estrangeiro & 0,421 & $\mathbf{0 , 1 6 7}$ & $\mathbf{0 , 1 4 6}$ & $\mathbf{0 , 1 1 0}$ & $\mathbf{0 , 1 0 8}$ & $\mathbf{0 , 1 2 7}$ \\
5 - Hábito de leitura de livros & 0,558 & 0,566 & 0,554 & 0,554 & 0,553 & 0,550 \\
& & & & & & \\
Número de observações (aproximado) & 5.000 & 740 & 1420 & 1890 & 1870 & 2.730 \\
\hline
\end{tabular}

Fonte: Enem 2005.

Nota: Valores em negrito têm diferenças significativas.

Simulação 1 = aumento de $5 \%$ na nota de não-brancos.

Simulação 2 = aumento de $10 \%$ na nota de não-brancos.

Simulação 3 = aumento de $10 \%$ na nota dos estudantes oriundos de escolas públicas.

Simulação 4 = aumento de $10 \%$ na nota dos estudantes oriundos somente das escolas públicas estaduais e municipais.

Simulação 5 = aumento de $5 \%$ na nota de não-brancos e de $10 \%$ na nota dos estudantes oriundos das escolas públicas estaduais e municipais. 
por faixa de renda. Foi possível verificar que há disparidades de condições tanto para se tornar apto a frequentar o ES como de acesso à universidade para os diferentes grupos de cor ou raça e também para os indivíduos de diferentes faixas de renda. Aqueles que frequentam o ES possuem renda mais alta e a proporção de brancos, entre estes, é maior do que a observada para os indivíduos aptos a ingressarem na universidade na RMBH.

As análises econométricas com modelos MQO permitiram mostrar que fatores relacionados à escola e ao nível socioeconômico influenciam em grande medida a nota obtida no Enem, sendo que a nota desse exame foi utilizada como uma proxi para os resultados de exames vestibulares. Os diferenciais quanto à cor/raça do indivíduo persistem mesmo quando controlados os efeitos da renda e escolaridade da família e tipo de escola. Entretanto, essas diferenças são menores do que as observadas para as demais variáveis, principalmente aquelas referentes ao nível socioeconômico e tipo de escola.

As simulações com diferentes tipos de bônus adicionais raciais e para os provenientes de escolas públicas mostraram que ambos são efetivos para aumentar a participação de pardos e pretos no corpo discente da UFMG, bem como a de grupos com menor renda no ES público. Assim, sugere-se que a adoção de medidas inclusivas para estudantes provenientes de escolas públicas estaduais e municipais pode ser muito eficiente como política de inclusão para grupos de pardos e pretos considerados desfavorecidos e também para extratos socioeconômicos mais vulneráveis. Além disso, dada a miscigenação observada no povo brasileiro, tal política não implica o problema de determinação de quem pertence ou não a grupo de cor desfavorecido ou a autodeclaração de cor dos indivíduos.

Deve-se ressaltar que a discussão em torno de grupos desfavorecidos em termos educacionais gira em torno da cor/raça ou do nível socioeconômico. Entretanto, existe uma crescente diferença entre os gêneros em favor das mulheres. Os homens apresentam indicadores muito inferiores às mulheres no ensino básico, o que se reflete no ES. Uma das razões desse fato é que pessoas do sexo masculino participam mais do mercado de trabalho e, como consequência, apresentam taxas de reprovação e de evasão muito superiores às mulheres. Assim, sugere-se que políticas voltadas para uma melhoria na inserção dos homens no ensino básico e também outras, como um bônus adicional por sexo, sejam propostas para mitigar os diferenciais de gênero.

Segundo as simulações realizadas, qualquer que seja a política de bônus adicional, mesmo com incremento significativo de estudantes originados dessas políticas, desde que esse incremento não seja demasiado, os novos ingressantes parecem ter potencial de aprendizado suficiente para que a UFMG não perca sua excelência de ensino. Isso ocorreria caso algumas políticas sejam concomitantemente implementadas, como maior inserção desses estudantes em cursos de língua estrangeira, além da ajuda monetária para que possam continuar os estudos em nível superior.

Desde a década de 1990, o Brasil tem apresentado melhoras significativas nos resultados educacionais em termos quantitativos, fato observado nesse trabalho pelo aumento marcante dos indivíduos aptos a ingressarem no ES, inclusive sendo verificada maior participação relativa dos grupos desfavorecidos. No entanto, esse resultado parcial positivo não deve desviar a atenção das mudanças na estrutura educacional, pois tornar o sistema mais inclusivo é importante para que os resultados educacionais brasileiros sejam cada vez mais positivos, indicando o papel decisivo das ações afirmativas no processo. Assim, deve-se destacar que políticas inclusivas no ES devem, necessariamente, vir integradas com uma melhoria geral da qualidade de ensino básico e ampliação dos diretos sociais, como é proposto pelo Plano de Desenvolvimento da Educação (MEC, 2009), com políticas voltadas para a educação, entre outros: Universidade Aberta, Fundeb, Piso Salarial Nacional do Magistério, Ideb, Ifet, etc.

Por fim, cabe destacar que a inclusão dos estudantes desfavorecidos no ES, como o recente aumento das vagas e me- 
Ihoria de inserção em universidades públicas via Reuni e PNAES, também envolve o ensino privado, que deveria desempenhar papel fundamental nesse processo. Para tanto, o PDE promove inovações nos me-

\section{Referências}

ADRIOLA, W.; NUNES, M.; SILVA, R. Caminho e descaminhos da universidade brasileira: em busca de um estudo avaliativo. 2009. Disponível em: <http://www.ufpi. $\mathrm{br} / \mathrm{mesteduc/eventos/iiiencontro/gt15/}$ caminhos_descaminhos.pdf $>$. Acesso em: set. 2009 .

ALMEIDA, V. UFMG: a construção do futuro. 2009. Disponível em: <http://qualeasuaufmg. blogspot.com/>. Acesso em: set. 2009.

BARROS, R. P.; MENDONÇA, R.; QUINTAES, G.; SANTOS, D. Determinantes do desempenho educacional do Brasil. Pesquisa e Planejamento Econômico, v. 31, n.1, p. 1-42, 2001.

BRAGA, M. M.; PEIXOTO, M. C. L. Censo socioeconômico e étnico dos estudantes de graduação da UFMG. Belo Horizonte: Editora UFMG, 2006.

BUCHMANN, C.; HANNUM, E. Education and stratification in developing countries: a review of theories and research. Annual Review of Sociology, v. 27, p. 77-102, 2001.

DOMINQUES, I. Os desafios dos próximos 80 anos. Revista da UFMG, ano 7, n. 13, 2008. Disponível em: <http://www.ufmg.br/diversa/13/artigo1.html>. Acesso em: set. 2009.

FERMAN, B.; ASSUNÇÃO, J. Affirmative action in university admission ad high school students' proficiency. In: XXVII ENCONTRO BRASILEIRO DE ECONOMETRIA. Anais... Natal: SBE, 2005.

FREITAS, M. Haverá cotas no UFMG? Boletim Informativo da UFMG, 2006. Disponível em: <http://www.ufmg.br/boletim/bol1535/ segunda.shtml>. Acesso em: out. 2007.

FRYER, R. G.; LOURY, G. C. Affirmative action and its mythology. Cambridge: National Bureau of Economic Research, 2005 (Working paper, 1.1464). canismos de financiamento do estudante, com mudanças no Fies e ainda via Prouni, sendo que estes programas também buscam a ampliação do ES e a inclusão de grupos desfavorecidos.

GOLGHER, A. B. O modelo Profluxo e indicadores derivados. In: RIOS-NETO, E.; RIANI, J. (Orgs.). Introdução à demografia da educação. Campinas: Abep, 2004

GOMES, J. B. O debate constitucional sobre ações afirmativas. In: SANTOS, R.; LOBATO, F. (Orgs.). Ações afirmativas, políticas públicas contra as desigualdades raciais. Rio de Janeiro: DP\&A, 2003.

GOMES, N. L.; MARTINS, A. A. (Orgs.). Afirmando direitos: acesso e permanência de jovens negros na universidade. Belo Horizonte: Autêntica, 2004.

HASENBALG, C.; SILVA, N. V. Educação e diferenças raciais na mobilidade ocupacional no Brasil. In: ENCONTRO ANUAL DA ANPOCS. Anais... Belo Horizonte: Anpocs, 1998.

HECKMAN, J. Sample selection bias as a specification error. Econometrica, n. 47, p. 153-161, 1979.

JACCOUD, L.; BEGHIN, N. Desigualdades raciais no Brasil: um balanço da intervenção governamental. Brasília: Ipea, 2002.

LEE, J.; BARRO, R. J. Schooling quality in a cross section of countries. Cambridge: National Bureau of Economic Research, 1997 (Working paper, 6.198).

MENEZES-FILHO, N. Os determinantes de desempenho escolar do Brasil. Instituto Futuro Brasil, 2007. (Texto para discussão). Disponível em: <http://www.eg.fjp.mg.gov. $\mathrm{br} /$ seminarioiv/download/menezes_filho. pdf>. Acesso em: jun. 2008.

MOEHLECKE, S. Ação afirmativa: história e debates no Brasil. Cadernos de Pesquisa, n. 117, p. 197-217, 2002.

Propostas de ações afirmativas

no Brasil: o acesso da população negra ao 
ensino superior. Dissertação (Mestrado). São Paulo, Faculdade de Educação da USP, 2000.

MORETTI, E. Estimating the social return to education: evidence from longitudinal and repeated cross-section data. Journal of Econometrics, n. 121, p. 175-212, 2004.

\section{MINISTÉRIODASCIDADES. Comoanda Belo}

Horizonte. Observatório das Metrópoles, 2008 (Texto para discussão). Disponível em: $<$ http://www.observatoriodasmetropoles. ufrj.br/Produtos_Mcidades/Vol10_Belo_ Horizonte.pdf>. Ácesso em: jun. 2008.

MINISTÉRIO DA EDUCAÇÃO. O Plano de Desenvolvimento da Educação - razões, princípios e programas. 2009. Disponível em: <http://portal.mec.gov.br/arquivos/pdf/ livromiolov4.pdf>. Acesso em: set. 2009.

PAIVA, M. L. R.; GOLGHER, A. Pobreza e desigualdade de renda em Belo Horizonte: uma análise para setores de habitação. In: $\mathrm{V}$ ENCONTRO NACIONAL DA ASSOCIAÇÃO BRASILEIRA DE ESTUDOS REGIONAIS E URBANOS. Anais... Recife: Venaber, 2007.

SACHSIDA, A.; LOUREIRO, P.; MENDONÇA, $M$. Um estudo sobre o retorno em escolaridade no Brasil. Revista Brasileira de Economia, v. 58, n. 2, p. 249-265, 2004.

SILVA, N. V.; HASENBALG, C. Recursos familiares e transições educacionais. In: WORKSHOP DE DEMOGRAFIA DA EDUCAÇÃO DA ASSOCIAÇÃO BRASILEIRA DE ESTUDOS POPULACIONAIS. Salvador: Abep, 2001.

WOOLDRIDGE, J. Introdução à econometria: uma abordagem moderna. São Paulo: Pioneira Thomson Learning, 2006.

\section{Resumen}

Una investigación sobre la aplicación del bono adicional como política de acción afirmativa en la Universidad Federal de Minas Gerais (UFMG)

Desde hace algunas décadas ha venido destacándose la importancia de las inversiones en educación para el desarrollo individual y regional. Un factor relevante, para que haya un incremento de capital humano en una región, es la inclusión de la mayor proporción posible de la población local en la escuela, en todos sus niveles de escolaridad. Entre las políticas que promueven esa inserción, se destacan las acciones afirmativas en el ámbito de la educación. Esas políticas, que incluyen el Bono Adicional abordado en este artículo, pretenden reducir las desigualdades de los diferentes grupos sociales, en particular en lo que se refiere a la atención escolar, combatiendo sistemáticamente la discriminación racial. En este trabajo, se discute la adopción del bono adicional en el examen de acceso a la universidad de la UFMG, comparándose, descriptivamente en el universo de la población de la $\mathrm{RMBH}$, los individuos aptos y os no-aptos de ingreso en la enseñanza superior, así como contrastando a éstos con los que efectivamente estudian en ese nivel de enseñanza. Se verificaron, por medio de simulaciones con los datos del Enem, los impactos que diferentes políticas de bono adicional tendrían desde el punto de vista de la inserción de los diferentes grupos raciales y rendimiento familiar. Se constató que, en algunos aspectos, esa política no incrementaría el cuerpo discente de la UFMG con individuos de menor potencial de aprendizaje, aunque ciertas políticas complementarias se deban tomar en relación con otros factores.

Palabras-clave: Discriminación. Acciones afirmativas. Cotas. Bono adicional. 


\begin{abstract}
An investigation into the application of the additional bonus as a policy of affirmative action at the Federal University of Minas Gerais, Brazil

In recent decades emphasis has been given to the importance of investments in education for both individual and regional development. One significant way to develop greater human capital in a region is to place as many persons as possible in schools of all levels of formal education. Especially important among policies to foster this inclusion are affirmative actions in the area of education. Such policies, which include the Additional Bonus, as discussed in this article, aim at reducing the inequalities between different social groups, especially in the area of education, in the constant struggle against racial discrimination. In this article the authors discuss the application of the Additional Bonus for the college entrance exam for the Federal University of Minas Gerais and descriptively compare those individuals living in the Belo Horizonte Metropolitan Area who are apt to enter higher education with those who are not. Those classified as apt were also compared with those who actually study at the university. Through simulations based on data from the National Enem Examination, the impacts that different policies of Additional Bonus would have was studied from the perspective of the insertion of persons of different ethnic groups and different family income levels. It was seen, for some factors, that this policy would not cause an impact at UFMG in terms of individuals with lower learning potential, although certain complementary policies should be implemented for other factors.
\end{abstract}

Keywords: Discrimination. Affirmative actions. Quotas. Additional Bonus.

Recebido para publicação em 05/06/2009 Aceito para publicação em 27/10/2009 